\title{
NBM-T-L-BMX-OS01, Semisynthesized from Osthole, Is a Novel Inhibitor of Histone Deacetylase and Enhances Learning and Memory in Rats
}

\author{
Ying-Chen Yang,, Chia-Nan Chen,, Carol-Imei Wu, ${ }^{1}$ Wei-Jan Huang, ${ }^{3}$ Tsun-Yung Kuo,, \\ Ming-Chung Kuan, ${ }^{1}$ Tung-Hu Tsai, ${ }^{4,5,6}$ Jing-Shi Huang, ${ }^{2}$ and Chung-Yang Huang ${ }^{2}$ \\ ${ }^{1}$ Department of Biotechnology and Animal Science, College of Bioresources, National Ilan University, Ilan 260, Taiwan \\ ${ }^{2}$ New Drug Research \& Development Center, Nature Wise Biotech \& Medicals Corporation, Taipei 112, Taiwan \\ ${ }^{3}$ Graduate Institute of Pharmacognosy, Taipei Medical University, Taipei 110, Taiwan \\ ${ }^{4}$ Institute of Traditional Medicine, School of Medicine, National Yang-Ming University, Taipei 112, Taiwan \\ ${ }^{5}$ Graduate Institute of Acupuncture Science, China Medical University, Taichung 404, Taiwan \\ ${ }^{6}$ Department of Education and Research, Taipei City Hospital, Taipei 103, Taiwan
}

Correspondence should be addressed to Ying-Chen Yang; ycyang@niu.edu.tw

Received 10 December 2012; Revised 19 February 2013; Accepted 25 February 2013

Academic Editor: Alfredo Vannacci

Copyright (c) 2013 Ying-Chen Yang et al. This is an open access article distributed under the Creative Commons Attribution License, which permits unrestricted use, distribution, and reproduction in any medium, provided the original work is properly cited.

\begin{abstract}
NBM-T-L-BMX-OS01 (BMX) was derived from the semisynthesis of osthole, isolated from Cnidium monnieri (L.) Cuss., and was identified to be a potent inhibitor of HDAC8. This study shows that HDAC8 is highly expressed in the pancreas and the brain. The function of HDAC8 in the brain has not been adequately studied. Because BMX enhances neurite outgrowth and cAMP response element-binding protein (CREB) activation, the effect of BMX on neural plasticity such as learning and memory is examined. To examine declarative and nondeclarative memory, a water maze, a passive one-way avoidance task, and a novel object recognition task were performed. Results from the water maze revealed that BMX and suberoylanilide-hydroxamic-acid-(SAHA-) treated rats showed shorter escape latency in finding the hidden platform. The BMX-treated animals spent more time in the target quadrant in the probe trial performance. An analysis of the passive one-way avoidance results showed that the BMX-treated animals stayed longer in the illuminated chamber by 1 day and 7 days after footshock. The novel object recognition task revealed that the BMXtreated animals showed a marked increase in the time spent exploring novel objects. Furthermore, BMX ameliorates scopolamine(Sco-) induced learning and memory impairment in animals, indicating a novel role of BMX in learning and memory.
\end{abstract}

\section{Introduction}

Chromatin, a densely packed higher-order complex structure containing DNA and histone proteins, is present in eukaryotic cells. Epigenetic modifications such as acetylation, methylation, and phosphorylation of histones are important in chromatin remodeling and the modulation of gene expression. All of these epigenetic modifications of amino acids may occur on the $\mathrm{N}$-terminal tail of histones. There are five major families of histones: $\mathrm{H} 1 / \mathrm{H} 5, \mathrm{H} 2 \mathrm{~A}, \mathrm{H} 2 \mathrm{~B}, \mathrm{H} 3$, and $\mathrm{H} 4$. Histones $\mathrm{H} 2 \mathrm{~A}, \mathrm{H} 2 \mathrm{~B}, \mathrm{H} 3$, and $\mathrm{H} 4$ are known as the core histones, while histones $\mathrm{H} 1$ and $\mathrm{H} 5$ are known as the linker histones [1]. Structural modifications of histones, especially
$\mathrm{H} 3$ and H4, mainly occur in acetylation or deacetylation of the $\mathrm{N}$-terminal tail through histone acetyltransferases (HATs) and histone deacetylases (HDACs). Mammalian HDACs are divided into 4 classes based on their function and structural homologies to yeast HDACs. Class I HDACs are HDACl, $-2,-3$, and -8. Class II HDACs are HDAC4, -5, -6, -7, -9 , and -10. Class III HDACs are SIRT 1-7, nicotinamideadenine-dinucleotide- $\left(\mathrm{NAD}^{+}\right.$-) dependent, and are involved in longevity. Class IV HDACs include HDAC11, which is $\mathrm{Zn}^{2+}$-dependent [2]. HDACs modulate both histone and nonhistone proteins. The nonhistone proteins, such as transcription factors (e.g., p53, STAT1, or STAT3), cytoskeleton proteins (e.g., $\alpha$-tubulin), and other cellular proteins (e.g., 
HSP90 or KU70), are targets for reversible acetylation as well. Acetylation of target nonhistone proteins has been suggested to influence protein stability, activity, localization, and binding efficiency with cofactors [3, 4].

Long-term memory formation relies on structural changes and gene transcription. Enriched environment stimulation is well known to enhance memory formation, and it has now been proven that enriched environmentactivated histone acetylation reverses memory impairment in p25-overexpressed brain-atrophic mice [5]. Sodium butyrate as a pandemic HDAC inhibitor mimics the effect of an enriched environment in restoring p25 transgenic mice memory as well [5]. This suggests that HDAC has a role in cognitive function. In brief, regarding the effect of Class I HDACs on memory, inactivation of HDAC1 by p25 precedes Alzheimer's disease and neuronal death [6]. Overexpression of HDAC1 does not affect memory in mice, whereas overexpression of HDAC2 impaired memory formation. Knockout of HDAC2 improves conditioned fear memory and synaptic plasticity [7]. The role of HDAC1 in memory is contrary to that of HDAC2. HDAC3-deficient mice showed longer retention time for novel objects in a novel object recognition experiment, indicating that HDAC3 also plays a negative role in memory formation [8]. Regarding HDAC8, few reports exist on its role in memory formation or neural plasticity.

To date, HDACis found to improve learning and memory are pan-HDAC inhibitors such as trichostatin A (TSA) [9], sodium butyrate [9], suberoylanilide hydroxamic acid (SAHA) [10], and valproic acid [11]. An increasing number of studies have implicated a role for SAHA in cognitive function and brain-related diseases [7, 12-14]. SAHA has been shown to cross the blood-brain barrier (BBB), increase histone acetylation in the brain, and reverse contextual memory deficits in a mouse model of Alzheimer's disease [15]. SAHA was shown to inhibit the deacetylase activity of Class I HDAC1, -2, -3, and -6 with little inhibition of HDAC8 [16]; SAHA enhances memory predominantly through inhibition of HDAC2 activity [7]. SAHA was approved by the US FDA for treating cutaneous T-cell lymphoma (CTCL) in 2006. Although SAHA shows potential in treating neurodegenerative diseases associated with cognitive impairment, however, knockdown of HDAC2 results in fragmented, detached cells, suggestive of apoptosis [17]. In addition, SAHA also inhibits HDAC1, and loss of HDAC1 leads to neurotoxicity $[6,18,19]$. SAHA might damage neuronal cells through inhibition of HDAC1 or HDAC2 enzyme activity which cannot be ruled out [20]. In this study, SAHA was selected among numerous HDAC inhibitors as a control because it is well studied and is regarded as the potential drug to treat neurodegenerative diseases and has less selectivity on HDAC8. Because of the possibility of cell damage from pan-HDACis, identifying a selective HDACi in learning and memory is a worthy pursuit.

Amnesia is a major symptom of aging and dementia in elderly people and Alzheimer's disease patients. Traditional Chinese medicines such as Tianma, Angelica sinensis, and Rehmannia glutinosa have been proven to ameliorate memory impairment [21-23]. Cnidium monnieri (L.) Cuss. shows effects of warming the kidney, activating the "yang" and blood, and is commonly used to treat kidney-Yangdeficient patients with the following symptoms: whitish tongue, fatigue, senescence, and impotence [24, 25]. Based on traditional Chinese medicine theory, Cnidium monnieri (L.) Cuss. is commonly used and ranked first in "Shen Nong's Herbal Classic." Osthole (7-methoxy-8-isopentenoxycoumarin), a major pharmacologically active constituent isolated from Cnidium monnieri (L.) Cuss., is a natural coumarin derivative. Research has implicated the role of osthole in combating erectile function [26] and has shown its properties of antiosteoporosis [27], antiproliferation [28], antiseizure [29], and antidiabetes [30]. Osthole also shows a neuroprotective effect on $\mathrm{MPP}^{+}$-induced cytotoxicity in PC12 cells [31]. Osthole also enhances the memory and ameliorates scopolamine- (Sco-) induced amnesia through its estrogenlike property in female rats $[32,33]$.

The enzymatic pocket of the HDACs was highly conserved. Therefore, most HDAC inhibitors act as paninhibitors. Knowledge on the contributions of individual HDAC family members is scant because of the lack of a specific HDAC inhibitor. In our study, osthole served as a source material that could be employed as a hydrophobic surface recognition cap for compound synthesis. A molecular docking analysis further suggested that the branched structure of osthole can provide isoforms with the selectivity of HDACs [34] to produce the active compound NBM-T-LBMX-OS01 (BMX). BMX was identified as a potent inhibitor of HDAC8. This study shows that HDAC8 is highly expressed in the pancreas and brain. Because BMX enhances neurite outgrowth and CREB activation, the effects of BMX on neural plasticity such as learning and memory are examined in this study.

\section{Materials and Methods}

2.1. Extraction and Isolation of Osthole. Seeds of Cnidium monnieri (L.) Cuss. (1 kg, dried weight) were purchased from a medicinal herb market in Taipei, Taiwan, in May 2008. The herb was extracted with acetone $(3 \times 10 \mathrm{~L})$ at $25 \pm 2^{\circ} \mathrm{C}$ for 2 weeks. After concentration of the combined extracts under reduced pressure, the residue (58.8 g) was suspended in $\mathrm{H}_{2} \mathrm{O}$ and then extracted with $n$-hexane : EtOAc $=70: 30$ (34.8 g). The extract $(10 \mathrm{~g})$ was chromatographed over a silica gel column and eluted with an $n$-hexane-EtOAc gradient system $(10: 0,9: 1,8: 2$, and $7: 3)$ to afford seven (F1-F4) fractions. The F3 (7.7 g) fraction was purified by HPLC (Phenomenex Luna C-18 silica gel column $[10 \times 250 \mathrm{~mm}]$, eluted with a mixture of $\mathrm{MeOH}$ and $\left.\mathrm{H}_{2} \mathrm{O}[80: 20, \mathrm{v} / \mathrm{v}]\right)$. Fractions containing osthole $(1,6.4 \mathrm{~g})$ were collected at retention times of 7.4 min. ${ }^{1} \mathrm{H}-\mathrm{NMR}\left(400 \mathrm{MHz}, \mathrm{CDCl}_{3}\right) 1.64\left(3 \mathrm{H}, \mathrm{s}, 5^{\prime}\right), 1.81$ $\left(3 \mathrm{H}, \mathrm{s}, 4^{\prime}\right), 3.48\left(2 \mathrm{H}, d, J=7.3 \mathrm{~Hz}, 1^{\prime}\right), 3.92\left(3 \mathrm{H}, \mathrm{s}, \mathrm{CH}_{3} \mathrm{O}\right)$, $5.17\left(1 \mathrm{H}, \mathrm{m}, 2^{\prime}\right), 6.20(1 \mathrm{H}, d, J=9.4 \mathrm{~Hz}, 4), 6.99(1 \mathrm{H}, d, J=$ $8.7 \mathrm{~Hz}, 6), 7.43(1 \mathrm{H}, d, J=8.7 \mathrm{~Hz}, 5), 7.84(1 \mathrm{H}, d, J=9.4 \mathrm{~Hz}$, 3), ${ }^{13} \mathrm{C}-\mathrm{NMR}\left(400 \mathrm{MHz}, \mathrm{CDCl}_{3}\right) 16.09\left(\mathrm{C}^{\prime}\right), 20.8\left(\mathrm{Cl}^{\prime}\right), 24.0$ $\left(\mathrm{C5}^{\prime}\right), 54.7\left(\mathrm{CH}_{3} \mathrm{O}\right), 107.1$ (C6), $111.2(\mathrm{C} 4), 112.5$ (C10), 116.7 (C8), 120.5 (C2 ${ }^{\prime}$ ), 126.2 (C5), 131.4 (C3'), 144.3 (C3), 152.0 (C9), 159.9 (C7), 161.5 (C2). HREIMS $m / z 244.30$ (calcd. for $\mathrm{C}_{15} \mathrm{H}_{16} \mathrm{O}_{3}$ 244.29). 
2.2. Preparation of 2-Hydroxy-3-prenyl-4-methoxy-trans-ethyl Cinnamate (2). The solution of $1(2.40 \mathrm{~g}, 10 \mathrm{mmol})$ in dry $\mathrm{EtOH}(20 \mathrm{~mL})$ was added dropwise to the mixture of sodium ethoxide $(1.36 \mathrm{~g}, 20 \mathrm{mmol})$ in dry EtOH $(20 \mathrm{~mL})$. The resulting solution was heated under nitrogen for $6 \mathrm{~h}$ and then diluted with dis- $\mathrm{H}_{2} \mathrm{O}(50 \mathrm{~mL})$, acidified with $1 \mathrm{~N} \mathrm{HCl}_{(\mathrm{aq})}$ to $\mathrm{pH} 4-5$, extracted with EtOAc $(50 \mathrm{~mL} \times 3)$, and dried over $\mathrm{Na}_{2} \mathrm{SO}_{4}$. After removal of EtOAc under reduced pressure, the residue was purified with silica gel (EtOAc $: n$-hexane $=10: 1$ ) to yield 2. ${ }^{1} \mathrm{H}-\mathrm{NMR}\left(500 \mathrm{MHz}, \mathrm{CDCl}_{3}\right): \delta 7.92(1 \mathrm{H}, d, J=$ $16.1 \mathrm{~Hz}), 7.33(1 \mathrm{H}, d, J=8.7 \mathrm{~Hz}), 6.49(1 \mathrm{H}, d, J=8.7 \mathrm{~Hz})$, $6.44(1 \mathrm{H}, d, J=16.1 \mathrm{~Hz}), 6.10(1 \mathrm{H}, \mathrm{s}), 5.20(1 \mathrm{H}, t, J=7.0 \mathrm{~Hz})$, $4.23(2 \mathrm{H}, q, J=7.2 \mathrm{~Hz}), 3.82(3 \mathrm{H}, \mathrm{s}), 3.42(1 \mathrm{H}, d, J=7.1 \mathrm{~Hz})$, $1.82(3 \mathrm{H}, \mathrm{s}), 1.75(3 \mathrm{H}, \mathrm{s}), 1.31(3 \mathrm{H}, t, J=7.2 \mathrm{~Hz})$.

\subsection{Preparation of 2-(4-Methoxybenzoxy)-3-prenyl-4-me-} thoxy-trans-ethyl Cinnamate (3). Methoxy benzyl chloride (3.44 mmol) was added to the mixture of $2(1.72 \mathrm{mmol})$ and $\mathrm{K}_{2} \mathrm{CO}_{3}(4.3 \mathrm{mmol})$ in acetone $(20 \mathrm{~mL})$. The resulting solution was heated under $\mathrm{N}_{2}$ overnight. After filtration to remove $\mathrm{K}_{2} \mathrm{CO}_{3}$, the filtrate was condensed under reduced pressure. The resulting residue was purified by gel (EtOAc: $n$-hexane $=15: 1)$ to yield $3 .{ }^{1} \mathrm{H}-\mathrm{NMR}(500 \mathrm{MHz}$, $\left.\mathrm{CDCl}_{3}\right): \delta 7.98(1 \mathrm{H}, d, J=16.1 \mathrm{~Hz}), 7.44(1 \mathrm{H}, d, J=8.7 \mathrm{~Hz})$, $7.40(2 \mathrm{H}, d, J=8.4 \mathrm{~Hz}), 6.92(2 \mathrm{H}, d, J=8.4 \mathrm{~Hz}), 6.71$ $(1 \mathrm{H}, d, J=8.7 \mathrm{~Hz}), 6.34(1 \mathrm{H}, d, J=16.1 \mathrm{~Hz}), 5.17(1 \mathrm{H}$, $t, J=6.4 \mathrm{~Hz}), 4.74(2 \mathrm{H}, \mathrm{s}), 4.25(2 \mathrm{H}, q, J=7.1 \mathrm{~Hz}), 3.86$ $(3 \mathrm{H}, \mathrm{s}), 3.83(3 \mathrm{H}, \mathrm{s}), 3.39(2 \mathrm{H}, d, J=6.5 \mathrm{~Hz}), 1.73(3 \mathrm{H}, \mathrm{s})$, $1.67(3 \mathrm{H}, \mathrm{s}), 1.33(3 \mathrm{H}, t, J=7.1 \mathrm{~Hz})$.

2.4. Preparation of 2-(4-Methoxybenzoxy)-3-prenyl-4-methoxy-trans-Cinnamate (4). The mixture of 3 (1.81 mmol) and $10 \% \mathrm{KOH} / \mathrm{MeOH}(20 \mathrm{~mL})$ was refluxed overnight under $\mathrm{N}_{2}$ and then diluted with dis- $\mathrm{H}_{2} \mathrm{O}(100 \mathrm{~mL})$, acidified with $2 \mathrm{~N} \mathrm{HCl}$ to $\mathrm{pH} 5-6$, and extracted with EtOAc $(50 \mathrm{~mL}$ $\times 3$ ). The combined EtOAc layer was dried over $\mathrm{Na}_{2} \mathrm{SO}_{4}$ and concentrated under a reduced pressure to yield $\mathbf{4}$, termed NBM-T-L-BMX-OS01 (BMX). ${ }^{1} \mathrm{H}-\mathrm{NMR}(500 \mathrm{MHz}$, $\left.\mathrm{CDCl}_{3}\right): \delta 8.06(1 \mathrm{H}, d, J=16.1 \mathrm{~Hz}), 7.47(1 \mathrm{H}, d, J=8.7 \mathrm{~Hz})$, $7.39(2 \mathrm{H}, d, J=8.5 \mathrm{~Hz}), 6.93(2 \mathrm{H}, d, J=8.5 \mathrm{~Hz}), 6.73$ $(1 \mathrm{H}, d, J=8.7 \mathrm{~Hz}), 6.35(1 \mathrm{H}, d, J=16.0 \mathrm{~Hz}), 5.18(1 \mathrm{H}$, $t, J=6.5 \mathrm{~Hz}), 4.76(2 \mathrm{H}, \mathrm{s}), 3.88(3 \mathrm{H}, \mathrm{s}), 3.82(3 \mathrm{H}, \mathrm{s}), 3.39$ $(1 \mathrm{H}, d, J=6.5 \mathrm{~Hz}), 1.73(3 \mathrm{H}, \mathrm{s}), 1.68(3 \mathrm{H}, \mathrm{s})$.

2.5. HDACs Activity Assay. HDAC 1-11 enzyme activity was determined by Reaction Biology Corp. (Malvern, PA, USA). The substrate was fluorogenic peptide from p53 residue 379382 (RHKKAc) and was measured with an excitation of $360 \mathrm{~nm}$ and an emission of $460 \mathrm{~nm}$. BMX and trichostatin A (TSA, a pan-HDACi as a standard positive control) were tested in the platform. Both compounds were assayed in serial dilution concentrations from a starting concentration of 20 to $0.0009 \mu \mathrm{M}$. Fluorescence intensity was measured using a fluorometric reader with an excitation of $360 \mathrm{~nm}$ and an emission of $460 \mathrm{~nm}$. The $\mathrm{EC}_{50}$ value was present at the concentration of test compounds to inhibit 50\% HDAC enzyme activity.
For the HDAC8 activity assay, the deacetylase activity of HDAC8 was measured using the commercially available Fluor-de-Lys-HDAC8 deacetylase substrate (Enzo, New York, NY, USA) according to the manufacturer instructions. In brief, the brain was dissected and was homogenized in PBS containing $0.32 \mathrm{M}$ sucrose $(\mathrm{pH} 7.4)$ by using a Teflon glass homogenizer. The homogenate was centrifuged at $1000 \times \mathrm{g}$ for $10 \mathrm{~min}$ to obtain the nuclei pellet. The resulting nuclei pellet was resuspended in a buffer containing $50 \mathrm{mM}$ Tris$\mathrm{HCl}, \mathrm{pH}$ 8.0, $137 \mathrm{mM} \mathrm{NaCl} 2.7 \mathrm{mM} \mathrm{KCl}$, and $1 \mathrm{mM} \mathrm{MgCl}$. To determine the HDAC activity, $10 \mu \mathrm{g}$ of nuclear extracts was incubated with a specific substrate $(100 \mu \mathrm{M})$ for $30 \mathrm{~min}$ at $37^{\circ} \mathrm{C}$, followed by the addition of a developer solution for $30 \mathrm{~min}$ at $37^{\circ} \mathrm{C}$. Fluorescence was measured using a Spectra Max Gemini XS fluorescent plate reader (Molecular Devices, Sunnyvale, CA, USA) with an excitation of $360 \mathrm{~nm}$ and an emission of $460 \mathrm{~nm}$. Data were normalized to swimming control, footshock control, and nontrained-control animals.

2.6. Animals. Adult male Sprague-Dawley rats (250-350 g) were purchased from the National Laboratory Center in Taiwan. Rats were housed (2 per cage) in a temperature$\left(22-24^{\circ} \mathrm{C}\right)$ and humidity- $(50 \%-60 \%)$ controlled room at the Animal Facility of Ilan University. Animals were housed in a room maintained on a $12 \mathrm{~h} / 12 \mathrm{~h}$ light/dark cycle with food and water available ad libitum. Animals were allowed to acclimatize to the room for 1 week before any experimental procedure was conducted. All experimental procedures were approved by the Guide for the Care and Use of Laboratory Animals, by the National Institutes of Health (NIH Publications No. 8023 , revised 1978), and were performed by people who had received the appropriate training by the National Laboratory Center in Taiwan. All experiments were also approved by the Ethical Committee of Animal Experimentation at Ilan University.

2.7. Drug Preparation and Treatment Schedule. SAHA was supplied by NatureWise Biotech and Medicals Corporation (Taipei, Taiwan). Scopolamine hydrochloride (Sco) was purchased from Sigma-Aldrich Co. (St. Louis, MO, USA). The BMX and SAHA stock $(100 \mathrm{mg} / \mathrm{mL})$ was dissolved in DMSO and diluted with saline to a final concentration of $0.5 \mathrm{mg} / \mathrm{mL}$ (in $0.5 \% \mathrm{DMSO} /$ saline). Sco was dissolved in saline to a final concentration of $0.15 \mathrm{mg} / \mathrm{mL}$ based on previous studies $[35,36]$. SD rats were randomly divided into 3 groups. For the naive animal experiments, the BMX-injected or SAHAinjected groups were injected with BMX $(5 \mathrm{mg} / \mathrm{kg} / \mathrm{d})$ or SAHA $(5 \mathrm{mg} / \mathrm{kg} / \mathrm{d})$ intraperitoneally $7 \mathrm{~d}$ prior to behavioral experiments and during the experimentation. The control group received the $0.5 \% \mathrm{DMSO} /$ saline injection. The injection volume was $10 \mu \mathrm{L} / \mathrm{g}$ of body weight. The injections were performed once per day. For the amnesia experiment, the protocol was adopted from previous studies [35, 36] with modifications. The Sco-injected (SAHA + Sco) or (BMX + Sco)-injected groups were injected with Sco $(1.5 \mathrm{mg} / \mathrm{kg} / \mathrm{d})$, SAHA ( $5 \mathrm{mg} / \mathrm{kg} / \mathrm{d})$ or BMX ( $5 \mathrm{mg} / \mathrm{kg} / \mathrm{d})$, intraperitoneally $7 \mathrm{~d}$ prior to behavioral experiments and during the experimentation. The control group received the $0.5 \% \mathrm{DMSO} /$ saline 
injection. The injection volume was $10 \mu \mathrm{L} / \mathrm{g}$ of body weight. The Sco injection was performed for $30 \mathrm{~min}$ before behavioral experiments, and the SAHA or BMX injection was conducted once daily at 5:00 PM 1 day prior.

2.8. RNA Extraction and Real-Time PCR. Total RNA from tissue was isolated by using the RNAspin Mini Kit (GE Healthcare, Waukesha, WI, USA). The cDNA was generated from total RNA with RevertAid Premium Reverse Transcriptase (Thermo Fisher Scientific, Waltham, MA, USA). Realtime PCR analysis was performed with the Rotor-Gene realtime PCR system (Qiagen, Hilden, Germany) by using the SYBR Green PCR Master Mix (Thermo Fisher Scientific) according to the instruction manual. The PCR parameters that were used are as follows: $95^{\circ} \mathrm{C}$ for $10 \mathrm{~min}$ for $1 \mathrm{cycle}, 95^{\circ} \mathrm{C}$ for $15 \mathrm{~s}$ followed by $60^{\circ} \mathrm{C}$ for $1 \mathrm{~min}$ for 40 cycles.

The primer sequences for $\mathrm{HDAC1}$ are as follows: forward: $5^{\prime}$-ATCGTCCTCACAAAGCCAAC- $3^{\prime}$ and reverse: $5^{\prime}$-TGT CCGTCTGCTGCTTATTG-3'. The primer sequences for HDAC2 are as follows: forward: $5^{\prime}$-TGCTGTCCTCGAGCT ACTGA-3' and reverse: $5^{\prime}$-TCCCTCATGGGAAAGTT GAC- $3^{\prime}$. The primer sequences for HDAC3 are as follows: forward: $5^{\prime}$-CTAGACCAGATCCGCCAGAC- $3^{\prime}$ and reverse: $5^{\prime}$-TGGCCTGCTGTAGTTCTCCT-3'. The primer sequences for HDAC8 are as follows: forward: $5^{\prime}$-CGCTAC CCCCGGTTTATATT- $3^{\prime}$ and reverse: $5^{\prime}$-CTTCTTGGC TGACCTTCTGG-3'. These sequences were designed based on the Primer Design Program "Primer 3" software (http://frodo.wi.mit.edu/primer3/). The primer sequences for HPRT, forward: $5^{\prime}$-GCAGACTTTGC TTTCCTTGG-3' and reverse: $5^{\prime}$-TCCACTTTCGCTGATGA CAC- $3^{\prime}$.

2.9. Blood-Brain Barrier Penetration of BMX. Adult male SD rats (250-350 g) were anesthetized intraperitoneally with $1.0 \mathrm{~g} / \mathrm{mL}$ of urethane and $0.1 \mathrm{~g} / \mathrm{mL}$ of $\alpha$-chloralose $(1.0 \mathrm{~mL} / \mathrm{kg}$, i.p.). The assay was adopted from previous studies [37, 38] with modifications. The femoral veins were catheterized with PE-50 tubing for BMX (10 mg/kg) administration. Before dosing and $15 \mathrm{~min}$ later, the blood samples $(0.3 \mathrm{~mL})$ were collected, followed by brain tissue dissection. The brain stem, cerebellum, cerebral cortex, hippocampus, striatum, and the rest of the brain were dissected from the whole brain after $15 \mathrm{~min}$ of blood sampling. The plasma sample $(50 \mu \mathrm{L})$ was mixed with $150 \mu \mathrm{L}$ methanol and $5 \mu \mathrm{L}$ honokiol $(10 \mu \mathrm{g} / \mathrm{mL}$, as internal control), followed by centrifugation at $16000 \times \mathrm{g}$ for $10 \mathrm{~min}$ at $4^{\circ} \mathrm{C}$. The supernatant $(20 \mu \mathrm{L})$ was analyzed using the HPLC-UV system. One gram of the brain sample was mixed with $5 \mathrm{~mL} \mathrm{50 \%} \mathrm{methanol} \mathrm{and} \mathrm{then} \mathrm{homogenized} \mathrm{at}$ $15000 \mathrm{rpm}$. The homogenized solution was centrifuged at $4000 \times \mathrm{g}$ for $10 \mathrm{~min}$. The supernatant of the homogenized solution $(50 \mu \mathrm{L})$ was mixed with $5 \mu \mathrm{L}$ honokiol $(10 \mu \mathrm{g} / \mathrm{mL}$, as internal standard) and $150 \mu \mathrm{L}$ methanol on a vortex for $10 \mathrm{~s}$. The denatured protein precipitate was separated by centrifugation at $16000 \times \mathrm{g}$ for $10 \mathrm{~min}$ at $4^{\circ} \mathrm{C}$. The supernatant $(20 \mu \mathrm{L})$ of the sample solution was injected into the HPLCUV system for analysis. Shimadzu liquid chromatography instrumentation (Nakakyo-ku, Kyoto, Japan) was used, which consisted of an LC-20AT pump, a DGU-20A5 on-line

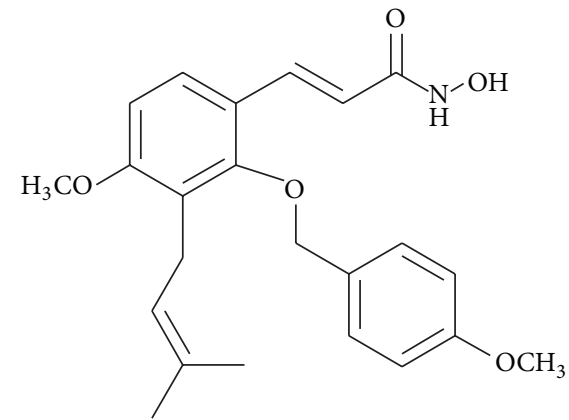

NBM-T-L-BMX-OS01 (BMX)

Figure 1: The NBM-T-L-BMX-OS01 (BMX) structure.

degasser, an SIL-20AC autosampler, and a SPD-M20A PDA detector. Separation was performed with an Agilent Zorbax extend-C18 $(150 \times 4.6 \mathrm{~mm}$ i.d., $5 \mu \mathrm{m})$ column. The mobile phase was conducted with methanol: $10 \mathrm{mM} \mathrm{KH}_{2} \mathrm{PO}_{4}(\mathrm{pH}$ 4.0) $(78: 22, \mathrm{v} / \mathrm{v})$ at a flow rate of $1 \mathrm{~mL} / \mathrm{min}$. The detector wavelength was set at $300 \mathrm{~nm}$. A stock solution $(200 \mu \mathrm{g} / \mathrm{mL})$ of BMX was prepared in methanol and diluted with $50 \%$ methanol at concentrations of $0.1,0.5,1,5,10,50$, and $100 \mu \mathrm{g} / \mathrm{mL}$ as a working solution. All 7-point calibration curves with concentrations of $0.01,0.05,0.1,0.5,1,5$, and $10 \mu \mathrm{g} / \mathrm{mL}$ were prepared. Quality control samples for the determination of interday and intraday variations, accuracy, precision, and extraction recovery were prepared in the same manner as the calibration samples.

2.10. Primary Hippocampal Cultured Neurons. The primary hippocampal culture was prepared as described previously [39]. To culture embryonic hippocampal primary neurons, pregnant Sprague-Dawley rats were purchased from the National Laboratory Center in Taiwan. The hippocampal tissue from the embryos of the Sprague-Dawley rats (E19) was dissociated with $100 \mathrm{U} / \mathrm{mL}$ of papain (Sigma-Aldrich) and plated onto poly-L-lysine-coated coverslips at a density of $1 \times$ $10^{4}$ cells $/ \mathrm{cm}^{2}$ with a minimal essential medium containing $5 \%$ calf serum, $5 \%$ horse serum, and $50 \mathrm{ng} / \mathrm{mL}$ insulintransferrin-selenite (Sigma-Aldrich). Three hours after plating, the medium was replaced with $2 \%$ of a B27-neurobasal medium (Invitrogen, Carlsbad, CA, USA) containing $0.5 \mathrm{mM}$ glutamine and $12.5 \mu \mathrm{M}$ glutamate.

2.11. MTT Assay. Cell viability was evaluated by an MTT (3-(4,5-dimethylthiazol-2-yl)-2,5-diphenyl tetrazolium bromide, Sigma-Aldrich) assay $24 \mathrm{~h}$ after SAHA and BMX treatment at concentrations of $0,1,2.5,5$, and $10 \mu \mathrm{M}$. The protocol was performed as described previously [40]. Cells were incubated with an MTT $(0.5 \mathrm{mg} / \mathrm{mL})$ reagent (SigmaAldrich) at $37^{\circ} \mathrm{C}$ for $1 \mathrm{~h}$. The MTT solution was removed, and DMSO was added to the wells shaken at room temperature for $1 \mathrm{~h}$. The amount of MTT formazan product was quantified by measuring its absorbance at 570 and $630 \mathrm{~nm}$ by using an ELISA plate reader (SpectraMax M2 Microplate Readers, Molecular Devices, Sunnyvale, CA, USA). 


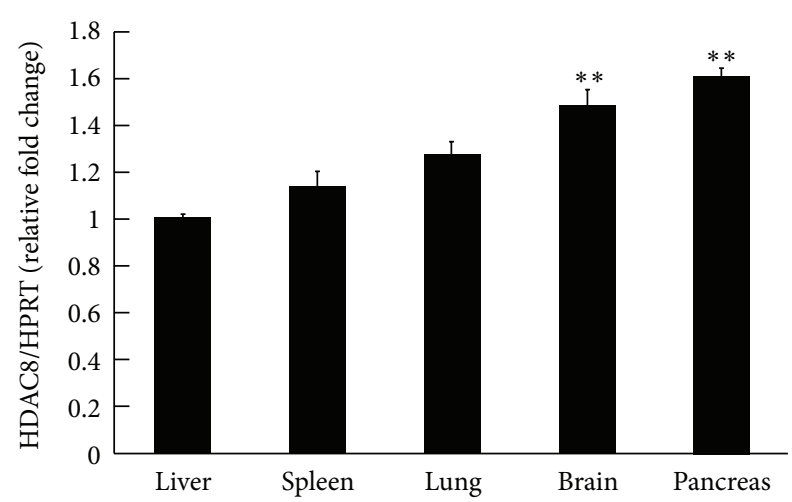

Figure 2: Level of HDAC8 mRNA in different tissues in naïve rats. Real-time PCR revealed that the pancreas and brain showed higher HDAC 8 mRNA expression. The data are the mean \pm SEM. $* *$, in the comparison of the control group. ${ }^{* *} P<0.01$. One-way ANOVA followed by Newman-Keuls comparisons.

2.12. Western Blot. The hippocampus tissue and primary hippocampal cells were lysed and sonicated in an RIPA buffer $(50 \mathrm{mM}$ Tris- $\mathrm{HCl}$ ( $\mathrm{pH} 7.4), 150 \mathrm{mM} \mathrm{NaCl}, 2 \mathrm{mM}$ EDTA, 1\% IGEPAL CA-630, $1 \mathrm{mM}$ phenylmethylsulfonyl fluoride (PMSF), $20 \mu \mathrm{g} / \mathrm{mL}$ pepstatin A, $20 \mu \mathrm{g} / \mathrm{mL}$ leupeptin, $20 \mu \mathrm{g} / \mathrm{mL}$ aprotinin, $50 \mathrm{mM} \mathrm{NaF}$, and $\left.1 \mathrm{mM} \mathrm{Na}_{3} \mathrm{VO}_{4}\right)$. The protocol was performed as described previously [41]. The lysate was resolved by $8 \%$ SDS-PAGE. The proteins resolved by SDS-PAGE were transferred to the PVDF membrane (Millipore, Bedford, MA, USA) and western blotting was conducted with the following antibodies: rabbit anti-acetyl histone 4 lysine 12 and mouse anti-histone 4 (Cell signaling, Danvers, MA, USA). The secondary antibodies used include the HRP-conjugated goat-anti-rabbit IgG antibody and HRPconjugated goat-anti-mouse IgG antibody (Millipore). The membrane was developed by reacting with a chemiluminescent HRP substrate (Millipore) and exposure to X-ray film. The protein bands were quantified using the NIH Image J Software.

2.13. Water-Maze Learning. The method was adopted from that of a previous study [41] with modifications. A plastic circular pool $2.0 \mathrm{~m}$ in diameter and $0.6 \mathrm{~m}$ in height was filled with water $\left(25 \pm 2^{\circ} \mathrm{C}\right)$ to a depth of $20 \mathrm{~cm}$. A circular platform ( $8 \mathrm{~cm}$ in diameter) was placed at a specific location from the edge of the pool and submerged $2-3 \mathrm{~cm}$ below the water surface. Water was made cloudy by adding toxicfree dye. Distinctive visual cues were set on the wall. For spatial learning, animals were subjected to 3 trials per day, with one trial early in the morning, one trial at noon, and another in the late afternoon. The training procedure lasted 4 days, and a total of 12 trials were given. This procedure was adopted because spaced training is a better paradigm to facilitate memory consolidation. For these trials, the rats were positioned at different starting points spaced equally around the perimeter of the pool in random order. They had $120 \mathrm{~s}$ to find the hidden platform. If a rat could not find the platform, it was guided to the platform and was allowed to remain there for $20 \mathrm{~s}$. The time each animal took to reach the platform was recorded as the escape latency. A probe trial of $120 \mathrm{~s}$ was given on day 5 to test their memory retention. The rats were placed in the pool with the platform removed, and the time they spent in each quadrant (Quadrants 1, 2, 3, and 4) was recorded. Quadrant 4 is the target quadrant. For the trained and swimming control experiments, rats in the trained group were subjected to the regular water maze learning procedure. At the end of the experiment, the rats were subjected to visible platform learning. For visible platform learning, a flag was mounted on the platform, and the platform was raised $2.5 \mathrm{~cm}$ above the surface of the water. In addition, the dye had not been added, so that the animals could see the location of the platform from the water. For each trial, the rats in the swimming control group swam for the same period as the trained group (use the mean latency value for each trial), with the difference of the visual cues and the platform having been removed.

2.14. Inhibitory Avoidance Learning Task. The apparatus consisted of a trough-shaped alley divided by a sliding door that separates an illuminated safety compartment and a dark compartment. A shock generator that produced current was connected to the floor of the dark compartment (UGO Basile, Comerio (VA), Italy). The method used was adopted from that of previous studies [42-44] with modifications. The behavioral task, including the training and testing procedures, was recorded between 8:00 AM and 6:00 PM. Before the experiment, the rats were habituated in a dim room for $1 \mathrm{~h}$ so that they could adjust to the environment. In the training phase, a rat was placed at the far end of the illuminated compartment facing away from the door. As the rat turned around, the door shut, and after $1 \mathrm{~s}$, a $1 \mathrm{~mA} / \mathrm{s}$ footshock was given twice. The rat was then removed from the alley and returned to its cage. At different times after training $(1 \mathrm{~d}$ and $7 \mathrm{~d}$ later), the retention test was given. Rats were tested after 1 day and 7 days in the same manner as in the training, but without receiving a shock. Testing was terminated either when the rat entered the dark chamber or after $600 \mathrm{~s}$ without entry. Rats that did not enter the dark compartment and reached the ceiling score of $600 \mathrm{~s}$ were removed from the alley and assigned as rats with good memory [45]. The animals placed in the dark compartment who received footshock $(1 \mathrm{~mA} / \mathrm{s}$ for $1 \mathrm{~s})$ directly were assigned to the footshock-only control group.

2.15. Novel Object Recognition Learning. The method used was adopted from that of a previous study [46] with modifications. During familiarization, rats were allowed to explore 2 identical objects in an open field box $(90 \times 70 \times 60 \mathrm{~cm})$ for $5 \mathrm{~min}$. The criteria used for exploration were a distance less than $1.5 \mathrm{~cm}$ between the rat and the object or direct contact with the object. During the retention test given $8 \mathrm{~h}$ later, the rats were returned to the same box, but one of the familiar objects was replaced with a novel object of approximately the same size. The time that each rat spent exploring the 2 objects during a $5 \mathrm{~min}$ period was recorded. The rats placed in the open field box without any objects for $5 \mathrm{~min}$ were assigned to the nontrained group. 


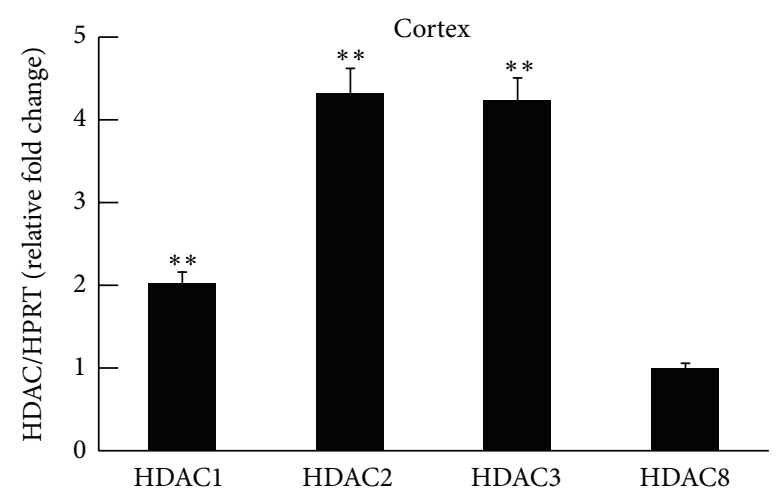

(a)

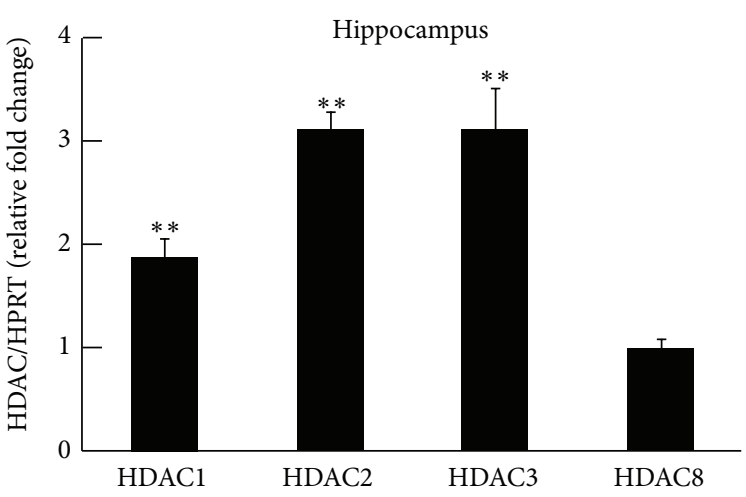

(b)

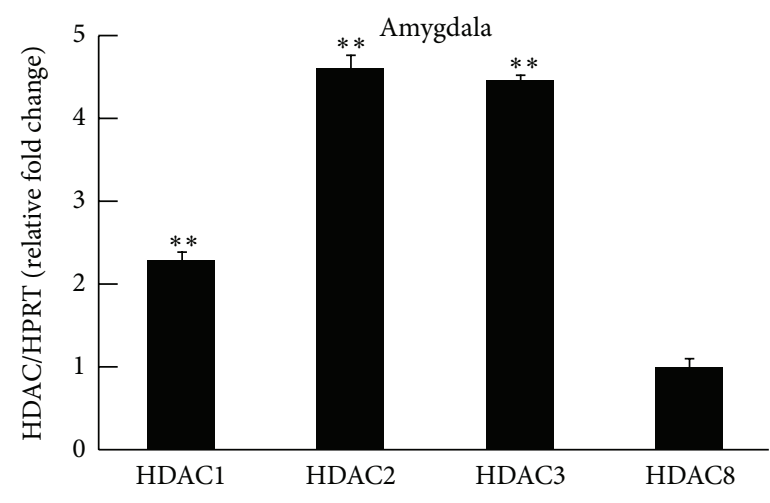

(c)

FIgURE 3: Level of HDAC8 mRNA in memory-related regions in naïve rats. Real-time PCR results showed that the expression of HDAC mRNA in the cortex is ranked HDAC2, HDAC3, HDAC1, and HDAC8, in that order, in the cortex (a), hippocampus (b), and amygdala (c). The data are the mean \pm SEM. $* *$, in the comparison of the control group. ${ }^{* *} P<0.01$. One-way ANOVA followed by Newman-Keuls comparisons.

2.16. Statistical Analysis. The biochemical data, part of watermaze data and passive one-way avoidance data, were analyzed with one-way analysis of variance (ANOVA), followed by post-hoc Newman-Keuls multiple-comparison test. The $q$ values represent those calculated from Newman-Keuls analysis. Part of the water maze data and novel object recognition data was analyzed with two-way ANOVA, followed by posthoc Newman-Keuls multiple-comparison test.

\section{Results}

3.1. NBM-T-L-BMX-OSO1 (BMX) Is Semisynthesized from Osthole and Is a Potent HDAC8 Inhibitor. Osthole was isolated from Cnidium monnieri (L.) Cuss. and was roughly $2 \%$ of the dry weight of this herb. In this study, osthole served as a source material that, through 3 steps of semisynthesis, produced the active compound NBM-T-L-BMX-OS01 (BMX) (397.46 Da) (Figure 1). To examine whether BMX is an HDAC inhibitor (HDACi), the enzymatic activity of 11 HDACs was evaluated by BMX and TSA (a pan-HDACi as a positive control was used in the commercial assay kit). BMX inhibited HDAC8 and HDAC3 with $\mathrm{EC}_{50} 0.831 \mu \mathrm{M}$ and $27.3 \mu \mathrm{M}$, respectively. TSA as a positive control is a pan-HDACi that significantly inhibited HDAC enzymes. BMX was 4963.6 times weaker in inhibiting HDAC3 enzyme activity than TSA (Table 1).
TABLE 1: The inhibition assay of HDACs activities by NBM-T-LBMX-OS01 (BMX) and trichostatin A (TSA).

\begin{tabular}{lcc}
\hline \multirow{2}{*}{$\begin{array}{l}\text { HDACs } \\
\left(\mathrm{EC}_{50}, \mathrm{M}\right)\end{array}$} & $\begin{array}{c}\text { HDACis } \\
\text { NBM-T-L-BMX-OS01 } \\
\text { (BMX) }\end{array}$ & $\begin{array}{c}\text { Trichostatin } \\
\text { A } \\
\text { HDAC1 }\end{array}$ \\
HDAC2 & - & $3.37 \times 10^{-9}$ \\
HDAC3 & - & $7.14 \times 10^{-9}$ \\
HDAC4 & $2.73 \times 10^{-5}$ & $5.55 \times 10^{-9}$ \\
HDAC5 & - & $9.51 \times 10^{-8}$ \\
HDAC6 & - & $6.99 \times 10^{-9}$ \\
HDAC7 & - & $9.96 \times 10^{-10}$ \\
HDAC8 & - & $2.46 \times 10^{-8}$ \\
HDAC9 & $8.31 \times 10^{-7}$ & $1.31 \times 10^{-7}$ \\
HDAC10 & - & $1.39 \times 10^{-8}$ \\
HDAC11 & - & $1.14 \times 10^{-8}$ \\
\hline
\end{tabular}

3.2. Tissue Distribution of HDAC8 $m R N A$. Naïve male SD rats (250-350 g) were euthanized, and the tissues were immediately dissected. Results from real-time PCR revealed that the pancreas and brain showed a higher HDAC8 mRNA 


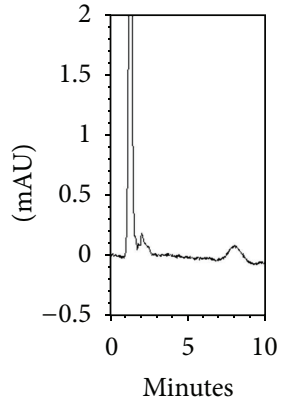

(A)

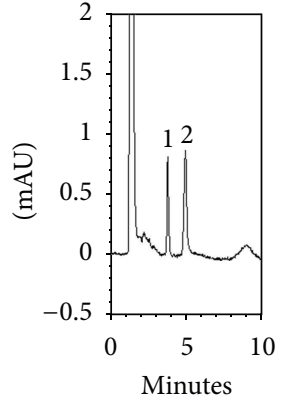

(B)

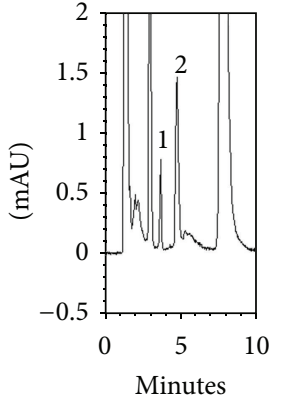

(C)

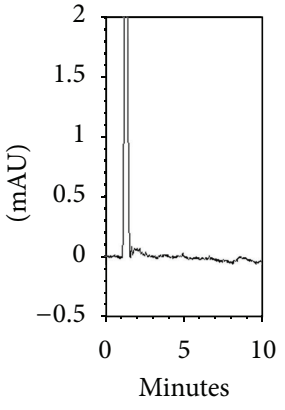

(A)

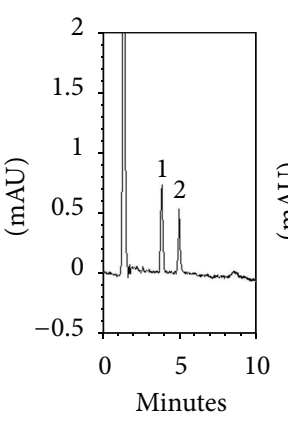

(B)

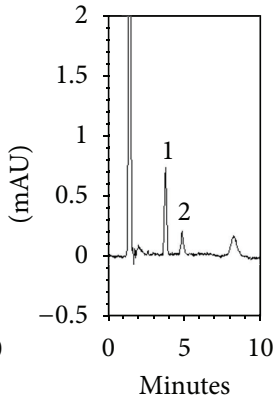

(C)

(a)

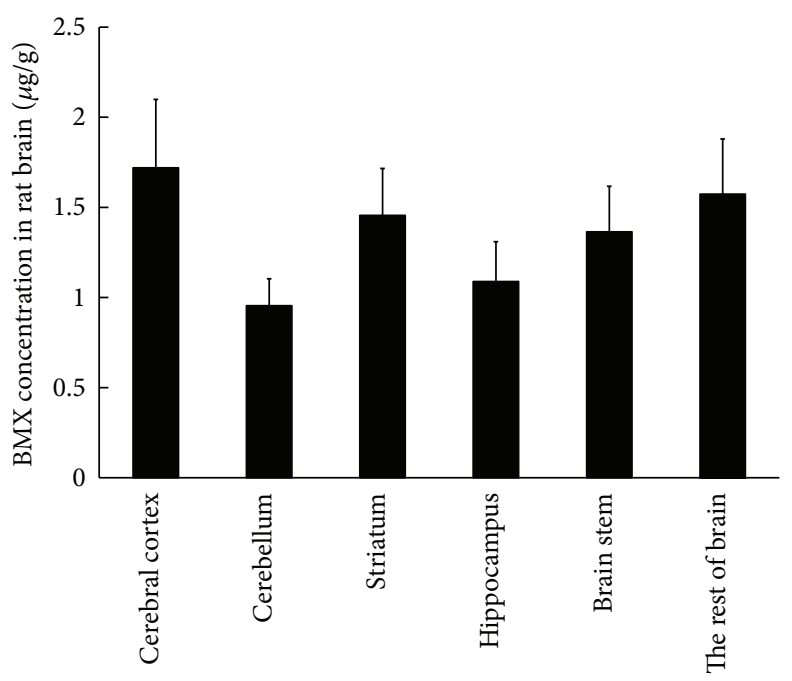

(b)

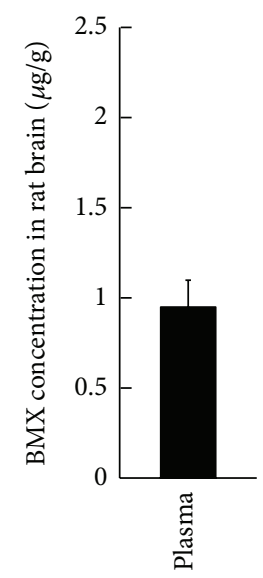

(d)

FIGURE 4: The BBB penetration assay of BMX. Chromatograms of plasma sample from (A) blank plasma; (B) blank plasma spiked with BMX $(1 \mu \mathrm{g} / \mathrm{mL}$, internal standard) and honokiol $(10 \mu \mathrm{g} / \mathrm{mL}$, internal standard); (C) plasma sample from rat plasma $15 \mathrm{~min}$ after honokiol (10 mg/kg, positive control, i.v.) and BMX (10 mg/kg, i.v.) administration. 1: honokiol; 2: BMX (a). Chromatograms of brain sample from (A) blank brain tissue; (B) blank brain spiked with BMX $(1 \mu \mathrm{g} / \mathrm{mL}$, internal standard) and honokiol (10 $\mu \mathrm{g} / \mathrm{mL}$, internal standard); (C) brain sample from the rat $15 \mathrm{~min}$ after honokiol (10 mg/kg, positive control, i.v.) and BMX (10 mg/kg, i.v.) administration. 1: honokiol; 2: BMX (b). Brain distribution profiles (c) and plasma concentration of BMX (d) $15 \mathrm{~min}$ after BMX (10 mg/kg, i.v.) was administered.

expression (1.6-fold and 1.5-fold, $q=7.64$ and 6.04, $P<0.01$ compared to the liver group, resp. $N=4$ in each group). Liver mRNA showed that the lowest expression was taken as 1. HPRT was used as an internal control (Figure 2).

3.3. Expression of HDAC1, $-2,-3$, and $-8 m R N A$ in the Cortex, Hippocampus, and Amygdala. The cortex, hippocampus, and amygdala are memory-related regions in the brain. Real-time PCR results showed that the expression of HDAC mRNA in the cortex is ranked HDAC2, HDAC3, HDAC1, and HDAC8, in that order (2.0-fold, 4.3-fold, and 4.2-fold, $q=11.92$, 15.37, and 14.89, resp., all $P<0.01$; compared to the HDAC8 group, resp. $N=8$ in each group). HPRT was used as an internal control. HDAC8 mRNA showed that the lowest expression was taken as 1 (Figure 3(a)). Similar results were identified in the hippocampus and amygdala tissues. The expression of HDAC in the hippocampus is ranked HDAC2, HDAC3, HDACl, and HDAC8, in that order (1.8-fold, 3.1-fold, and 3fold, $q=4.25,9.01$, and 7.62, resp., all $P<0.01$, compared to the HDAC8 group, resp. $N=8$ in each group) (Figure 3(b)). The expression of HDAC in the amygdala is ranked HDAC2, HDAC3, HDACl, and HDAC8, in that order (2.2-fold, 4.9fold, and 4.6-fold, $q=4.81,16.32$, and 18.11, resp., all $P<0.01$, compared to the HDAC8 group, resp. $N=8$ in each group) (Figure 3(c)).

3.4. BMX Is Able to Penetrate the Blood-Brain Barrier (BBB). BMX $(10 \mathrm{mg} / \mathrm{kg}$ ) was intravenously (i.v.) injected into rats (each $N=6$ ). The chromatograms of the plasma sample are as follows: Panel (A) was the blank plasma; Panel (B) was the blank plasma spiked with honokiol $(10 \mu \mathrm{g} / \mathrm{mL}$, internal standard, Peak 1) and BMX (1 $\mu \mathrm{g} / \mathrm{mL}$, Peak 2); and Panel (C) was the plasma sample from the rat plasma 15 min after honokiol and BMX (10 mg/kg, i.v.) administration (Figure 4(a)). After blood sampling, the brain tissue was dissected. Panel (A) was the blank brain tissue; Panel (B) was the blank brain tissue spiked with honokiol $(10 \mu \mathrm{g} / \mathrm{mL}$, internal standard, Peak 1) and BMX (1 $\mu \mathrm{g} / \mathrm{mL}$, internal standard, Peak 2$)$; and 


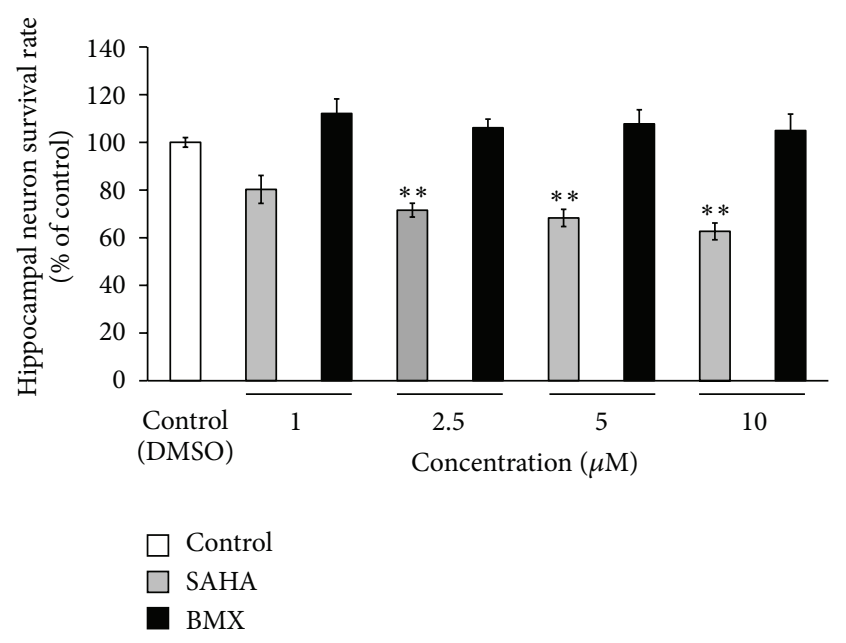

FIGURE 5: Effects of SAHA and BMX on primary hippocampal neuron viability by an MTT assay. SAHA and BMX $(1,2.5,5$, and $10 \mu \mathrm{M})$ were applied to primary hippocampal neurons at DIV 5 for $24 \mathrm{~h}$. SAHA reduced the survival rate of hippocampal neurons at concentrations of $2.5,5$, and $10 \mu \mathrm{M}$. BMX showed little neurotoxic effect on the primary hippocampal neurons. The data are the mean \pm SEM. $* *$, in the comparison of the control group. ${ }^{* *} P<0.01$. One-way ANOVA followed by Newman-Keuls comparisons.

Panel (C) was the brain tissue sample from the rats $15 \mathrm{~min}$ after honokiol and BMX (10 mg/kg, i.v.) administration (Figure 4(b)). BMX penetrated the BBB and was detected in brain areas including the cerebral cortex, cerebellum, striatum, hippocampus, brain stem, and the rest of the brain (Figure 4(c)). After brain dissection, the plasma sample was collected and assayed for BMX concentration (Figure 4(d)).

\subsection{BMX Shows Less Neurotoxicity Than SAHA on Primary} Hippocampal Neurons. Using an MTT cell survival assay, SAHA reduced the survival rate of the hippocampal neurons at concentrations of $2.5,5$, and $10 \mu \mathrm{M}$. BMX did not inhibit the survival rate of primary hippocampal neurons (Figure 5). BMX was shown to increase the neurite branch and neurite length in the primary hippocampal neurons. SAHA increased the neurite length in particular (see Supplementary Figure 1 available online at http://dx.doi.org/10.1155/2013/514908). Moreover, both SAHA and BMX increased CREB phosphorylation at Ser133 in hippocampal cultured neurons (Supplementary Figure 2(a)), as well as CRE-mediated promoter activity in HEK293T cells (Supplementary Figure 2(b)). These observations suggest that BMX might play a role in neural plasticity (e.g., learning and memory).

3.6. BMX and SAHA Enhance Spatial Learning. Because of the ability of both BMX and SAHA [14] to penetrate the BBB, these drugs were administered intraperitoneally $(5 \mathrm{mg} / \mathrm{kg} / \mathrm{d})$ to naïve rats (each $N=10$ ). Rats receiving SAHA and BMX injections spent less time in finding the hidden platform $\left(F_{2,27}=4.94, P<0.05\right)$. A marked decrease in escape latency was observed as early as Trial 4 in both BMX- and SAHA-treated groups $(q=6.59$ and 3.71, $P<0.01$, resp.) (Figure 6(a), upper). BMX and SAHA shortened escape latency, especially from day $2(q=4.81, P<0.05$, in a comparison of the control versus BMX-treated groups; $q=3.23, P<0.05$, in a comparison of the control versus SAHA-treated groups) (Figure 6(a), lower). Further probe trial tests for memory retrieval showed that rats receiving BMX spent more time in the quadrant where the platform had been placed (Quadrant 4 is the target quadrant) ( $q=$ $3.68, P<0.05)$. SAHA-treated rats showed no difference compared with the control group $(P>0.05)$ (Figure 6(b), upper). The representative swimming patterns are shown in Figure 6(b) (lower). Swimming speed was also analyzed by a 2 min video recording in a pool without a platform to examine whether drugs have an effect on the motor activities of animals. During this recording, the speed is quantified as distance divided by time. Swimming speed was unaltered in all 3 groups $\left(F_{2,27}=0.04, P>0.05\right)$ (Figure 6(c)) and in their visible platform learning performance $\left(F_{2,27}=1.1, P>0.05\right)$ (Figure $6(\mathrm{~d})$ ). At the end of the experiment, the hippocampus was dissected for histone 4 lysine 12 acetylation (AcH4K12) and HDAC8 activity analysis. Because swimming itself might induce stress responses, and because stress has been reported to activate numerous signaling molecules, including HDAC [47], swimming control animals were taken as another control animal. Water-maze-trained-control animals showed higher $\mathrm{H} 4 \mathrm{~K} 12$ acetylation compared with the swimming control animals $(q=2.98, P<0.05)$. SAHA-treated animals showed the highest H4K12 acetylation $(q=6.33, P<0.01$, compared with the swimming control animals), and BMXtreated animals showed similar $\mathrm{H} 4 \mathrm{~K} 12$ acetylation to trainedcontrol animals $(q=2.88, P<0.05$, compared with the swimming control animals; $P>0.05$, compared with the trained-control animals) (Figure 6(e)). Water-maze-trainedcontrol animals showed higher HDAC8 activity compared with the swimming control animals $(q=4.07, P<0.01)$. SAHA-treated animals did not increase HDAC8 activity $(q=$ $0.32, P>0.05$, compared with the trained-control animals), and the BMX-treated animals showed increased HDAC8 activity $(q=3.01, P<0.05$, compared with the trainedcontrol animals) (Figure 6(f)).

3.7. BMX, but Not SAHA, Enhances Passive One-Way Avoidance Tasks. Naïve rats were randomly divided into control, SAHA, and BMX treatment groups $(5 \mathrm{mg} / \mathrm{kg} / \mathrm{d}$, each $N=$ 9). A one-trial footshock was delivered when rats entered a dark chamber from an illuminated chamber. Latency to enter the dark chamber 1 day and 7 days following footshock served as a measure of short-term and long-term memory retention. The cut-off latency was set at $600 \mathrm{~s}$. Before receiving the footshock, all the rat groups spent approximately the same time entering the dark chamber from an illuminated chamber $(P>0.05$, Figure 7(a)). Only BMX-treated rats showed significant retention time in the illuminated chamber 1 day after the footshock $(q=3.51, P<0.05$, in a comparison of the control versus BMX-treated groups on day 1) and 7 days after the footshock $(q=3.8, P<0.05)$ (in a comparison of the control versus BMX group on day 7) (Figure 7(b)). No difference in retention performance between the control 

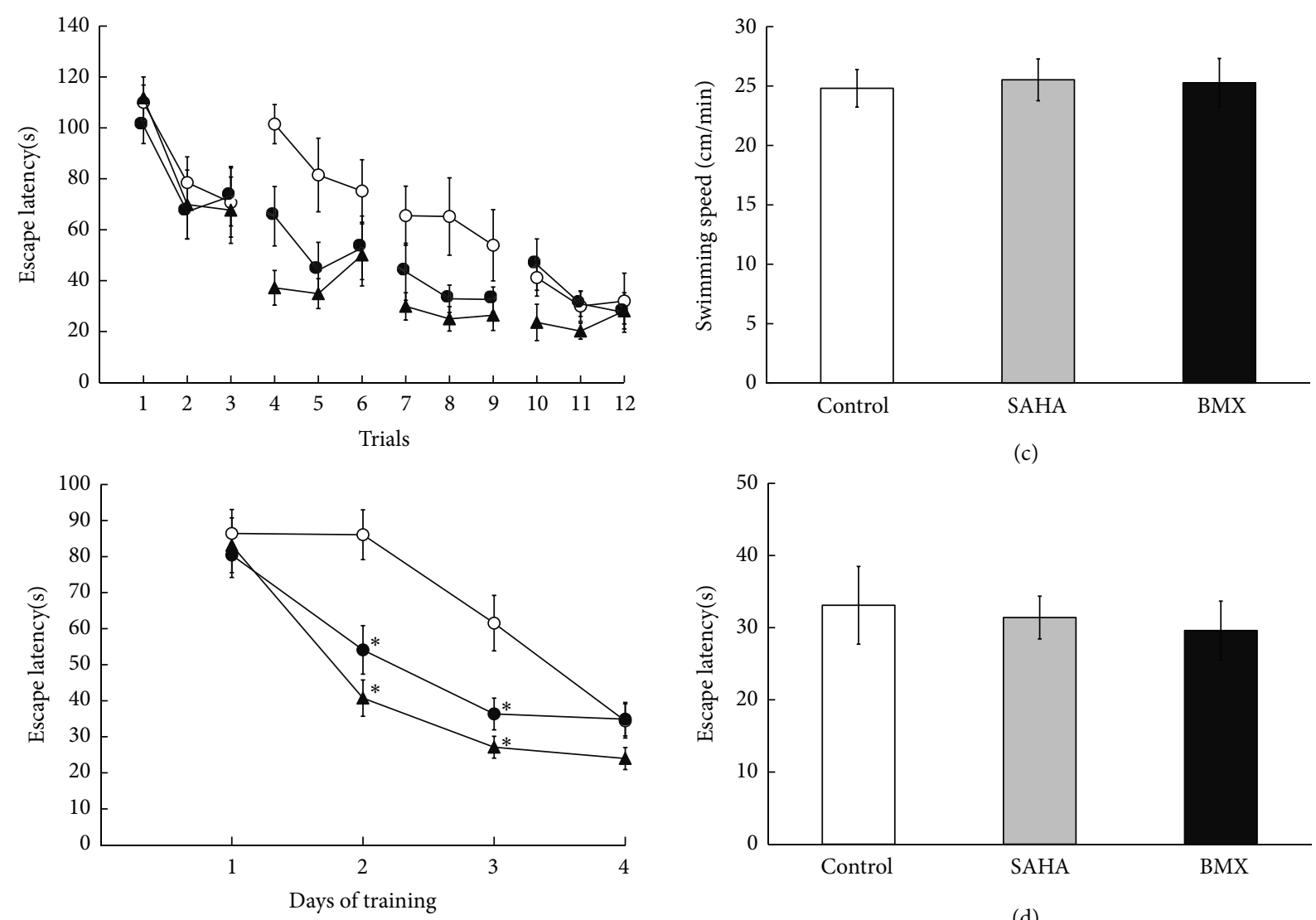

-O- Control

$\rightarrow$ SAHA

$\neg$ BMX

(a)
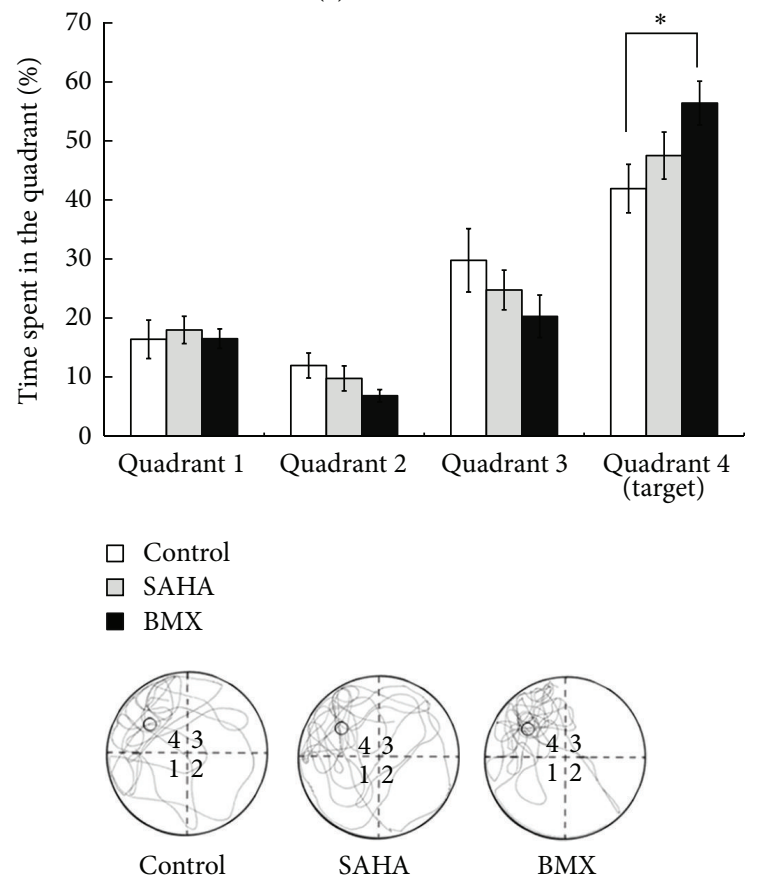

(d)

Control

SAHA

BMX

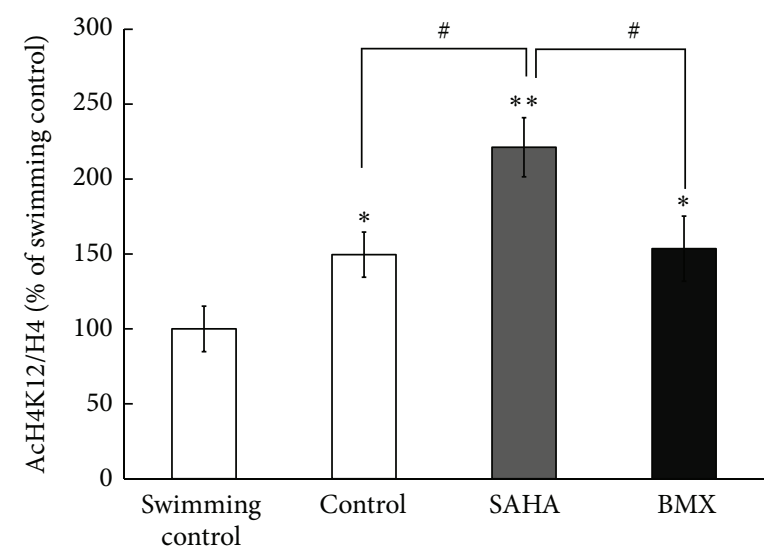

(b)

(e)

Figure 6: Continued. 


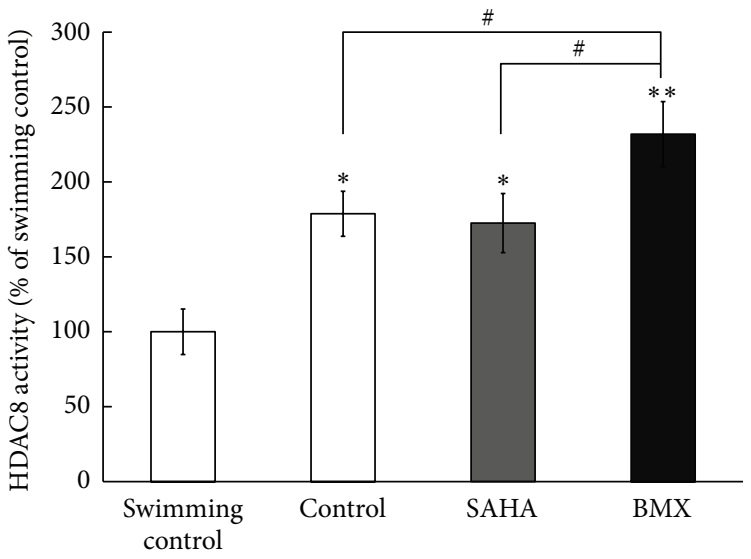

(f)

FIGURE 6: Effects of SAHA and BMX on water-maze memory acquisition and retrieval in rats. Control, SAHA-, and BMX-treated rats were subjected to water-maze training. The escape latency(s) of each water-maze learning trial ((a), upper) and the mean escape latency of each learning day ((a), lower) were recorded. On day 5, the hidden platform was removed, and the rats were allowed to swim for the probe trial test for $2 \mathrm{~min}$. The time spent in each quadrant was recorded ((b), upper). The representative swimming pattern from the probe trial test is shown ((b), lower). We analyzed the swimming speed (c) and the escape latency of each water-maze learning trial in the visible platform (d) to rule out any motor, visual, or motivation side effect of BMX. After the experiment, the hippocampus was dissected for western blotting of histone 4 lysine 12 acetylation (AcH4K12). A representative gel pattern and quantitative analysis of AcH4K12 and the H4 level in the hippocampus (e). Quantitative analysis of HDAC8 activity in the hippocampus after the probe trial test (f). The data are the mean \pm SEM. *, in the comparison of the control group; \#, in the comparison between groups. ${ }^{*, \#} P<0.05 ;{ }^{* *} P<0.01$. A two-way ANOVA followed by Newman-Keuls comparisons was applied for (a) and (b). A one-way ANOVA followed by Newman-Keuls comparisons was applied for (c), (d), (e), and (f).

and SAHA groups was noticed $(P>0.05)$. At the end of the experiment, the amygdala was dissected for $\mathrm{H} 4 \mathrm{~K} 12$ acetylation and HDAC8 activity analysis. Rats that received only the footshock without training were taken as the footshock control animals. Trained-control animals showed higher $\mathrm{H} 4 \mathrm{~K} 12$ acetylation compared with the footshock-only control animals $(q=3.24, P<0.05)$. SAHA-treated animals showed the highest H4K12 acetylation $(q=5.99, P<0.01$, compared with the footshock-only control animals), and the BMX-treated animals showed similar H4K12 acetylation to the trained-control group $(P>0.05$, compared with the trained-control animals) (Figure $7(\mathrm{c})$ ). Trained-control animals showed higher HDAC8 activity compared with the footshock-only control animals $(q=3.5, P<0.05)$. SAHAtreated animals did not have increased HDAC8 activity $(P>$ 0.05 , compared with the trained-control animals), and the BMX-treated animals showed the highest HDAC8 activity ( $q=3.62, P<0.05$, compared with the trained-control animals) (Figure $7(\mathrm{~d})$ ).

3.8. BMX Enhances Novel Object Recognition Tasks. In the novel object recognition task, the animals (each $N=9$ ) did not show any preference for the left object (LO) or the right object (RO) during recognition training (pre-) (all $P>0.05$ ) (Figure 8(a)). After Eight h (post-), a novel object (NO) replaced the RO. All rats showed a preference for the NO. Rats receiving BMX $(5 \mathrm{mg} / \mathrm{kg} / \mathrm{d})$ showed a significant exploratory preference for the NO with respect to time spent exploring the object (Figure 8(a)) compared to the control and SAHA $(5 \mathrm{mg} / \mathrm{kg} / \mathrm{d})$ treated rats $(q=4.47, P<0.05$; $q=4.51, P<0.05)$. At the end of the experiment, the hippocampus was dissected for $\mathrm{H} 4 \mathrm{~K} 12$ acetylation and HDAC8 activity analysis. The animals placed in the open field box for $5 \mathrm{~min}$ without any objects were assigned to the nontrained group. The trained-control animals showed higher $\mathrm{H} 4 \mathrm{~K} 12$ acetylation compared with the nontrained animals $(q=3.61, P<0.05)$. The SAHA-treated animals showed the highest H4K12 acetylation $(q=6.42, P<$ 0.01 , compared with the nontrained animals), and BMXtreated animals showed similar H4K12 acetylation to the trained-control animals $(P>0.05$, compared with the trained-control animals) (Figure 8(b)). The trained-control animals showed higher HDAC8 activity compared with the nontrained animals $(q=3.52, P<0.05)$. The SAHA-treated animals did not have further increased HDAC8 activity $(P>$ 0.05 , compared with the trained-control animals), and the BMX-treated animals showed increased HDAC8 activity $(q=$ 3.71, $P<0.05$, compared with the trained-control animals) (Figure 8(c)).

3.9. BMX and SAHA Ameliorate Sco-Induced Memory Impairment in Spatial Learning. The treatment of Sco, a muscarinic receptor antagonist in animals and humans, causes impairments in learning and memory [48]. The Sco-induced amnesia animal model is frequently used in research on aging and dementia $[23,35,49,50]$. Sco $(1.5 \mathrm{mg} / \mathrm{kg} / \mathrm{d})$ and BMX $(5 \mathrm{mg} / \mathrm{kg} / \mathrm{d})$ were injected for 7 days prior to the behavioral test and persisted to be injected during the experimentation (each $N=10$ ). Rats receiving Sco injection showed longer escape latency in finding the hidden platform $\left(F_{3,36}=18.75\right.$, $P<0.01)$. A marked improvement in escape latency was 


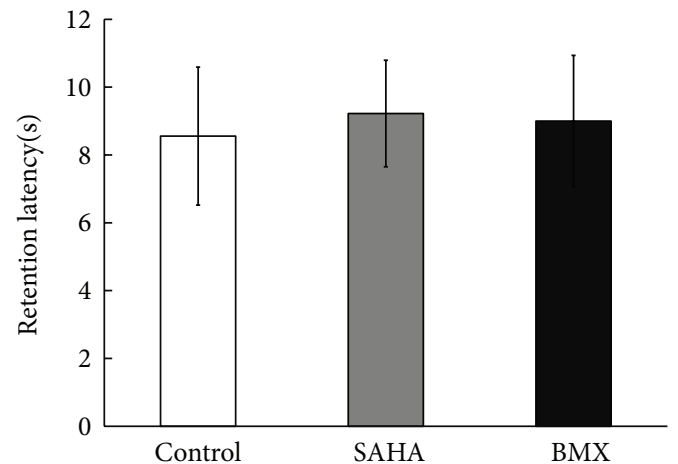

(a)

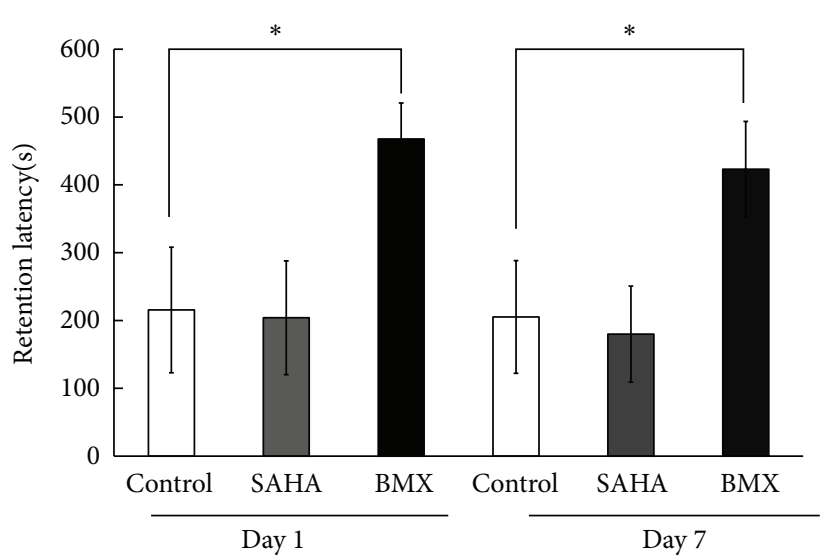

(b)

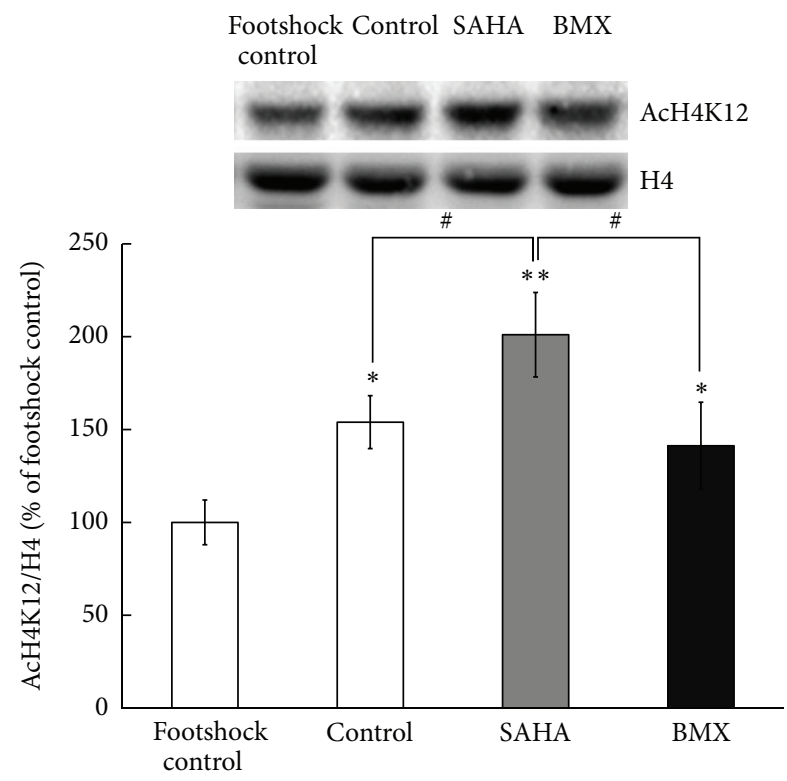

(c)

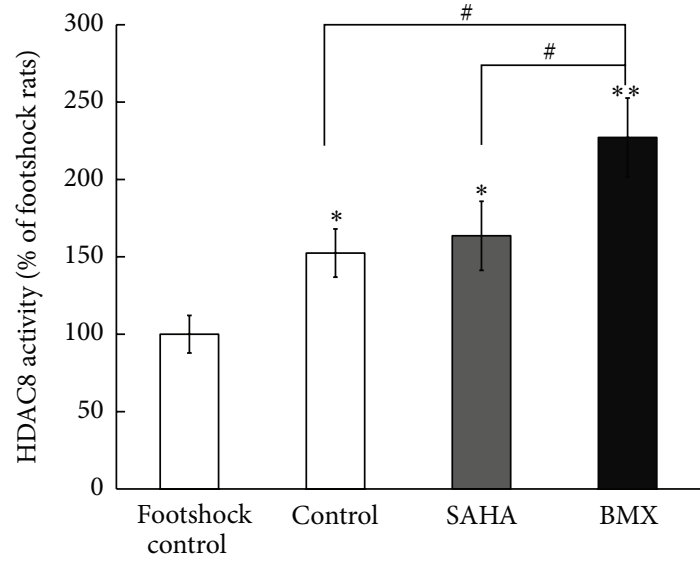

(d)

FIGURE 7: Effects of SAHA and BMX on passive one-way inhibitory avoidance learning in rats. Control, SAHA-, and BMX-injected rats were subjected to passive one-way inhibitory avoidance learning. Retention time in an illuminated compartment before footshock did not show any difference (a). Retention time in an illuminated compartment 1 day and 7 days after footshock was recorded (b). After the experiment, the amygdala was dissected for AcH4K12 western blotting. A representative gel pattern and quantitative analysis of AcH4K12 and the H4 level in the amygdala at 7 days after footshock (c). The HDAC8 activity in the amygdala 7 days after footshock was analyzed (d). The data are the mean \pm SEM. $*$, in the comparison of the control group; \#, in the comparison between groups. ${ }^{*, \#} P<0.05 ;{ }^{* *} P<0.01$. One-way ANOVA followed by Newman-Keuls comparisons.

observed as early as Trial 2 in (BMX + Sco)-treated groups $(q=4.02, P<0.05)$ (Figure 9(a), upper). BMX attenuates Sco-induced longer escape latency, especially from day 1 ( $q=$ 3.36, $P<0.05$, in a comparison of the Sco versus (BMX + Sco)-treated groups) (Figure 9(a), lower). An improvement in escape latency was observed from Trial 8 in (SAHA + Sco)-treated groups $(q=3.46, P<0.05)$ (Figure 9(a), upper). SAHA attenuates Sco-induced longer escape latency, especially from day $3(q=3.89, P<0.05$, in a comparison of the Sco versus (SAHA + Sco)-treated groups) (Figure 9(a), lower). Further probe trial tests for memory retrieval showed that rats receiving Sco spent less time in the quadrant where the platform had been placed (Quadrant 4 is the target quadrant) ( $q=5.79, P<0.01$, when compared with control group). (BMX + Sco)-treated and (SAHA + Sco)-treated rats spent more time in the target quadrant $(q=7.39, P<$ $0.01 ; q=3.26, P<0.05$, when compared with Sco-treated group) (Figure 9(b), upper). The representative swimming patterns are shown in Figure 9(b) (lower). Swimming speed was unaltered in all 4 groups $(P>0.05)$ (Figure $9(\mathrm{c}))$ and in their visible platform learning performance $(P>0.05)$ (Figure 9(d)).

3.10. BMX Ameliorates Sco-Induced Memory Impairment in Passive One-Way Avoidance Tasks. Naïve rats were randomly divided into control, Sco, (SAHA + Sco), and (BMX + Sco) 


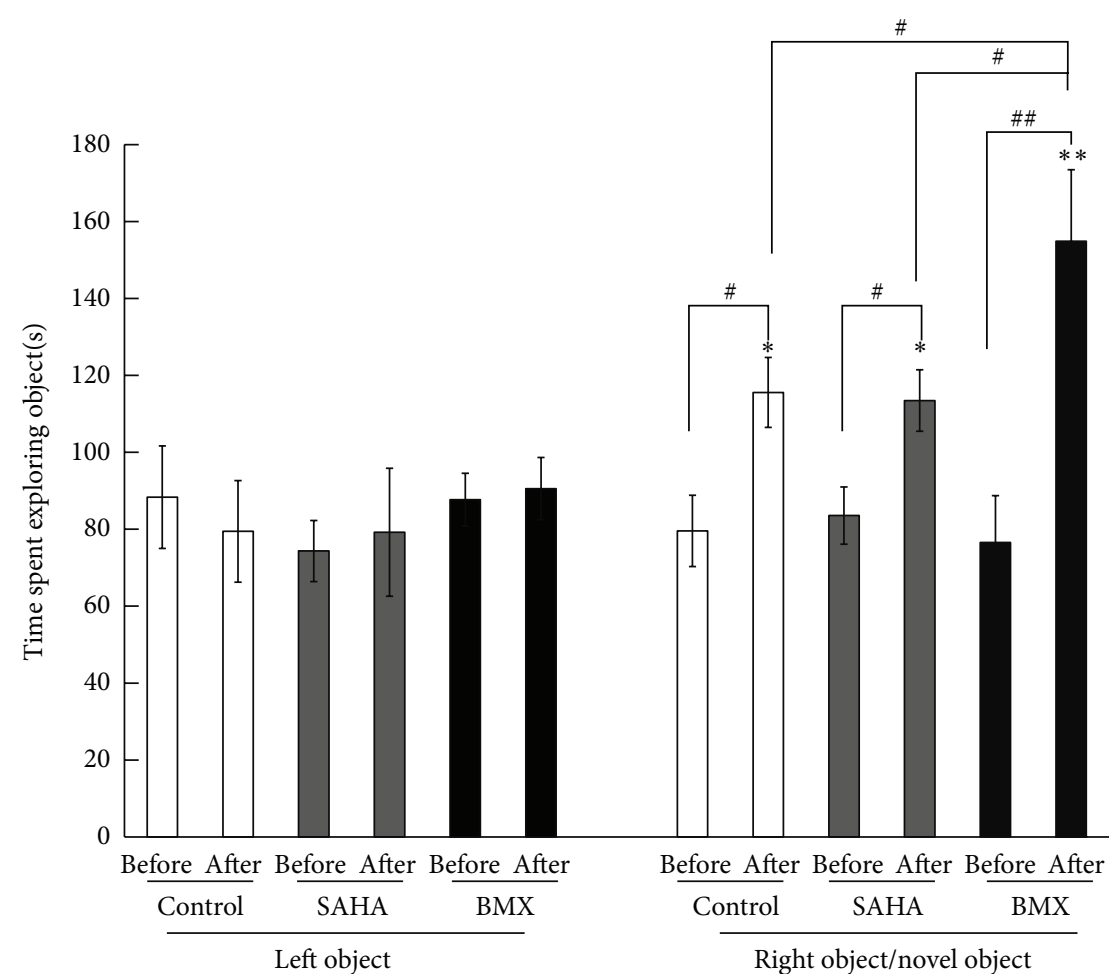

(a)

Nontrained Control SAHA BMX control
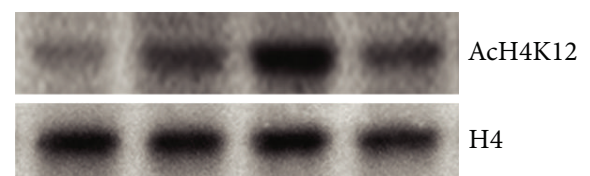

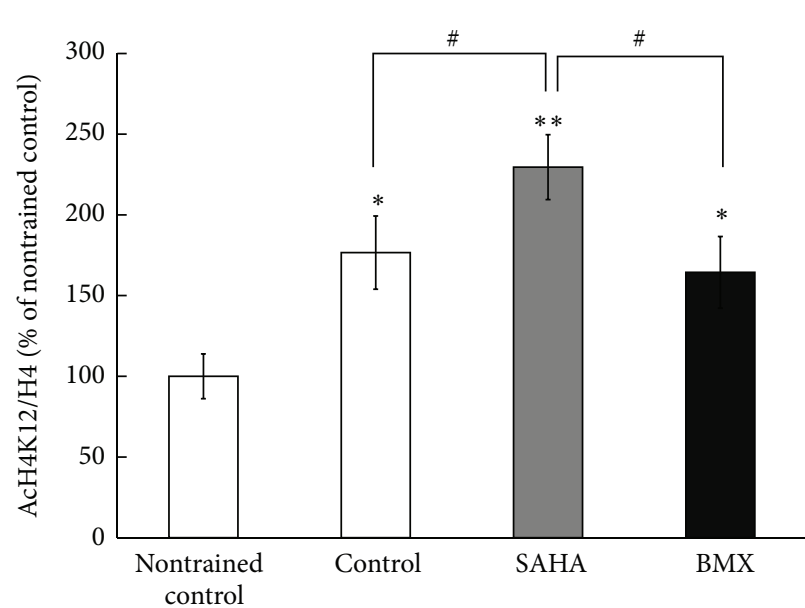

(b)

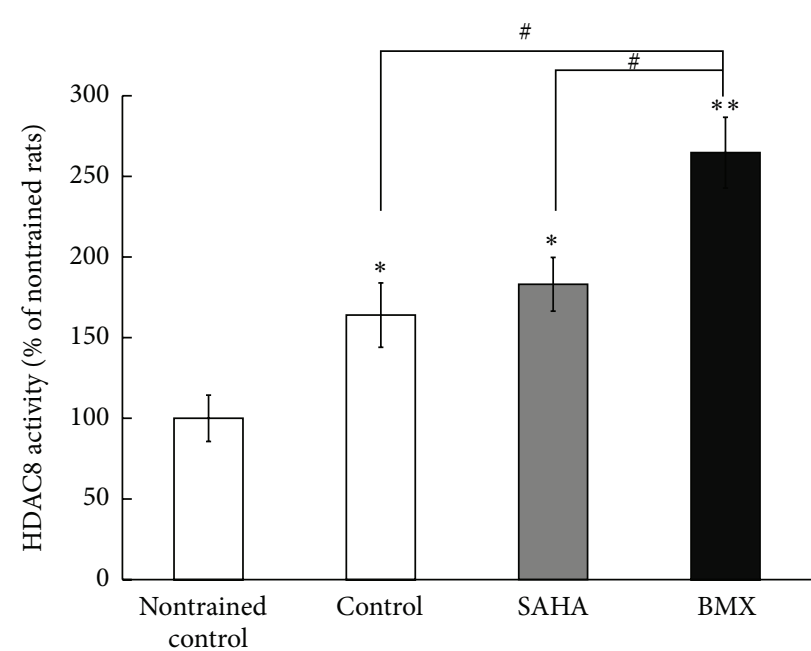

(c)

FIGURE 8: Effects of SAHA and BMX on the novel object recognition test in rats. Control, SAHA-, and BMX-injected rats were subjected to the novel object recognition test. The retention time(s) spent in exploring the left object, right object, and novel object before (pre-) and after (post-) the right object was replaced with the novel object was recorded (a). After the experiment, the hippocampus was dissected for AcH4K12 western blotting. A representative gel pattern and quantitative analysis of AcH4K12 and the H4 level from the rat hippocampus (b). The HDAC8 activity in the hippocampus was analyzed (d). The data are the mean \pm SEM. $*$, in the comparison of the control group; \#, in the comparison between groups. ${ }^{*, \#} P<0.05 ;{ }^{* *, \# \#} P<0.01$. A two-way ANOVA followed by Newman-Keuls comparisons was applied for (a). A one-way ANOVA followed by Newman-Keuls comparisons was applied for (b) and (c). 
treatment groups (each $N=8)$. Sco $(1.5 \mathrm{mg} / \mathrm{kg} / \mathrm{d}$ ), SAHA $(5 \mathrm{mg} / \mathrm{kg} / \mathrm{d})$, or BMX ( $5 \mathrm{mg} / \mathrm{kg} / \mathrm{d}$ ) was injected for 7 days prior to the behavioral test and persisted to be injected during the experimentation. Before receiving the footshock, all the rat groups spent approximately the same time entering the dark chamber from an illuminated chamber $(P>0.05$, Figure 10(a)). Sco-treated rats showed less retention time in the illuminated chamber 1 day after the footshock $(q=4.12$, $P<0.05$, in a comparison of the control versus Sco-treated groups on day 1) and 7 days after the footshock $(q=4.3, P<$ 0.05 ) (in a comparison of the control versus Sco-treated group on day 7). (SAHA + Sco)-treated rats showed less retention time in the illuminated chamber 1 day after the footshock ( $q=3.12, P<0.05$, in a comparison of the control versus (SAHA + Sco)-treated groups on Day 1) and 7 days after the footshock $(q=3.9, P<0.05)$ (in a comparison of the control versus (SAHA + Sco)-treated group on Day 7). No difference in retention performance between the control and (BMX + Sco) groups was noticed $(P>0.05)$. (BMX + Sco)-treated rats spent more time in the illuminated chamber 1 day after the footshock $(q=4.53, P<0.05$, when compared with Scotreated group) and 7 days after the footshock $(q=3.51, P<$ 0.05, when compared with Sco-treated group) (Figure 10(b)).

3.11. BMX Ameliorates Sco-Induced Memory Impairment in Novel Object Recognition Tasks. In the novel object recognition task, Sco $(1.5 \mathrm{mg} / \mathrm{kg} / \mathrm{d})$ and BMX $(5 \mathrm{mg} / \mathrm{kg} / \mathrm{d})$ were injected for 7 days prior to the behavioral test and persisted to be injected during the experimentation. The animals (each $N=8$ ) did not show any preference for the left object (LO) or the right object (RO) during recognition training (pre-) (all $P>0.05$ ). After Eight h (post-), a novel object (NO) replaced the RO. Control and (BMX + Sco)-treated rats showed a preference for the NO $(q=3.79, P<0.05 ; q=3.92$, $P<0.05)$. Rats receiving Sco or (SAHA + Sco) injection showed no exploratory preference for the NO with respect to time spent in exploring the $\mathrm{RO}(P>0.05)$ (Figure 11).

\section{Discussion}

This study reports on a potent HDAC8 inhibitor BMX with little neurotoxicity, but with great potential for memory improvement. Our study shows that HDAC8 is highly expressed in the pancreas and the brain. The expression level of HDAC in memory-related regions, including the cortex, hippocampus, and amygdala, is ranked HDAC2, HDAC3, HDAC1, and HDAC8, in that order. Although the expression of HDAC8 is the lowest, the loss of HDAC8 causes embryonic lethality [51]. The HDAC8-selective inhibitor suppressed neuroblastoma cell proliferation $[17,52]$. Knockdown of HDAC8 initiates neuronal differentiation such as an outgrowth of the neurite-like structure in human neuroblastoma cell lines [52]. BMX, a potent HDAC8 inhibitor, shows less cytotoxicity and induces significant neurite outgrowth including neurite branch and length in primary hippocampal neuron culture (Supplementary Figure 1). In Supplementary Figure 2, BMX is shown to increase CREB phosphorylation at Ser133 and also enhance CRE-mediated promoter activity. CREB and CRE-mediated gene expression levels are necessary for memory formation in many studies [53]. Neural plasticity, including neurite outgrowth and CREB activation, is necessary for long-term memory formation. Taken together, this suggests a role of BMX in memory formation and neural plasticity.

This is the first study to search for the role of the osthole-derived compound BMX in memory formation. To examine declarative and nondeclarative memory, a water maze, a passive one-way avoidance task, and a novel object recognition task were performed. The Morris water maze is a paradigm for spatial memory formation, which is an early deficit of Alzheimer's disease. In the water-maze task, BMXtreated rats even showed significant memory retrieval performance compared to SAHA-treated rats in the probe trial test. Neither BMX nor SAHA affects their visual discrimination ability, motor coordination, and motivational state. The water maze is a task that relies on the hippocampal function. The dorsal hippocampus is critical for several types of memory, including spatial and working memory [54], and it has been recently implicated in object recognition memory [55].

Numerous aversive conditioning procedures have been used to study memory regarding emotional experiences in rats. Passive-avoidance response is extensively used to screen drugs affecting learning and memory. The amygdala and other connected regions are critical for passive-avoidance learning. The training procedure comprises a single trial and is based on the innate preference of rodents for a dark chamber and the avoidance of punishment. The application of strong electric shock ( $1 \mathrm{~mA}$ or higher) is an appropriate method to examine memory retention in vivo [42-44]. In our experiment, an electric footshock (1 $\mathrm{mA})$ was delivered. We found that BMX-treated, but not SAHA-treated, rats stayed longer in the illuminated chamber, and this effect lasted at least 7 days.

The novel object recognition test has become popular for testing recognition memory in rodents and for testing the effects of amnesic drugs. It is based on the premise that rodents explore a novel object more than a familiar one, but only if they remember the familiar one. This tendency is shared by human declarative memory [56]. The results of the novel object recognition task revealed that only BMX-treated rats spend more exploratory time on the novel object $8 \mathrm{~h}$ later. Transcription of immediate-early genes (e.g., $A r c$ ) triggers the labile memory to lasting memory in the modification of neuronal networks [57]. For example, an Arc mRNA increase occurs at least for $8 \mathrm{~h}$ in the hippocampal formation following a spatial behavioral experience [58]. Whether BMX plays a unique role in transforming fragile memory into long-term memory must be further studied. Other HDAC inhibitors such as sodium butyrate also transform a labile learning event into a remembered long-term event in the novel object recognition test [59].

In addition, BMX not only facilitates learning and memory in naïve animals, but also ameliorates Sco-induced memory impairment. The Sco-induced amnesia rats were adopted to evaluate the antiamnesic efficiency [49]. The animals injected with Sco featured impaired memory performance in the Morris water-maze test, novel object recognition test, and step-through passive avoidance test $[36,60,61]$. 

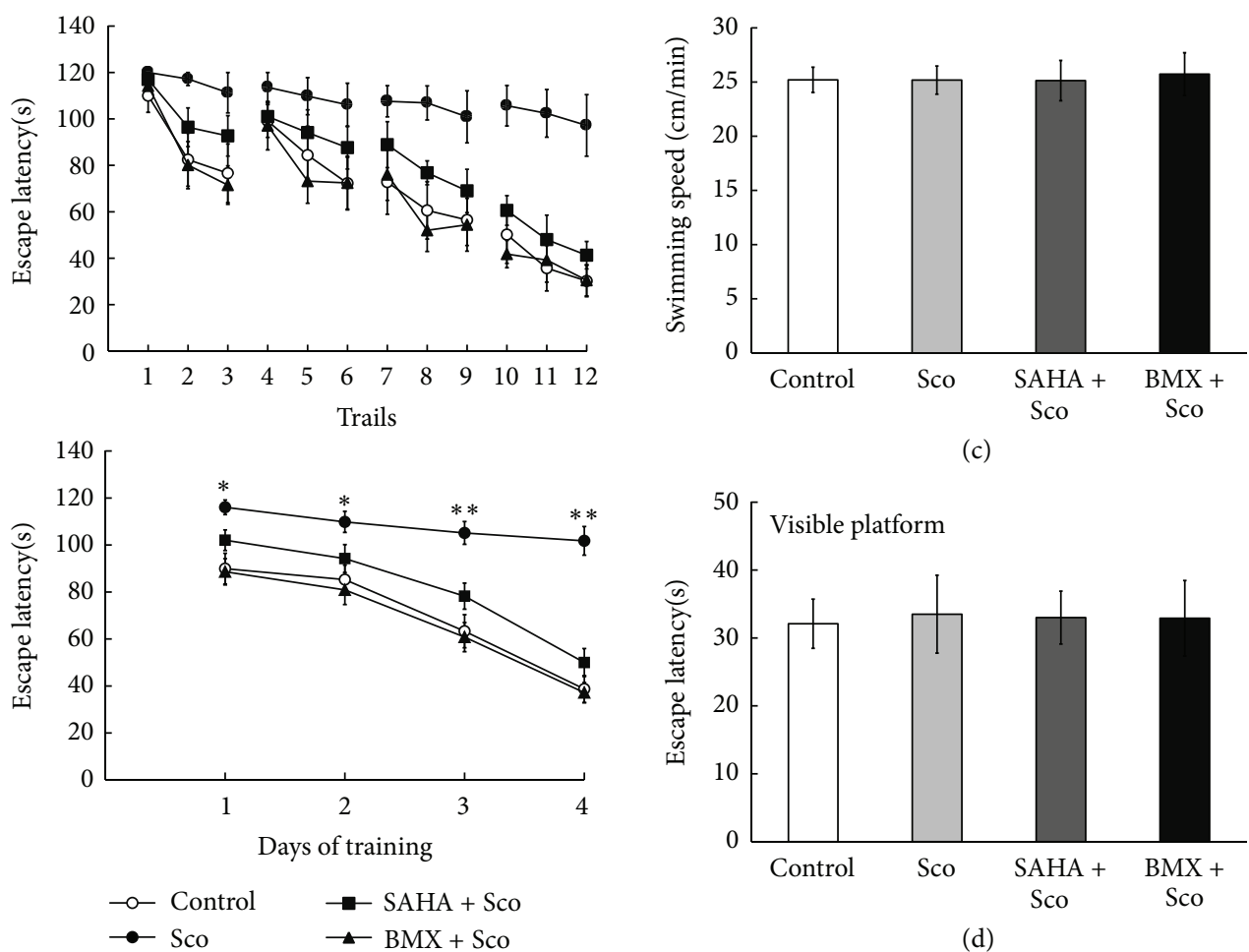

(c)

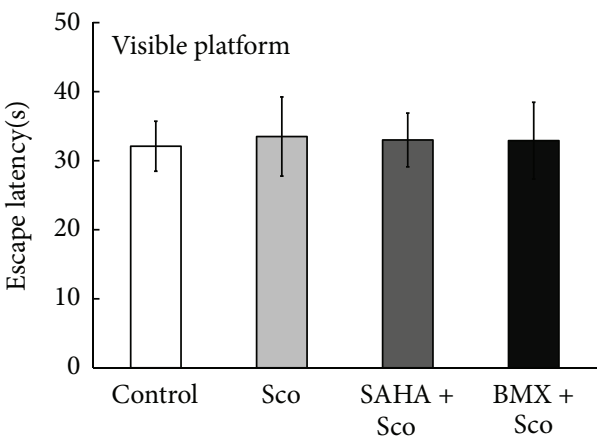

(a)

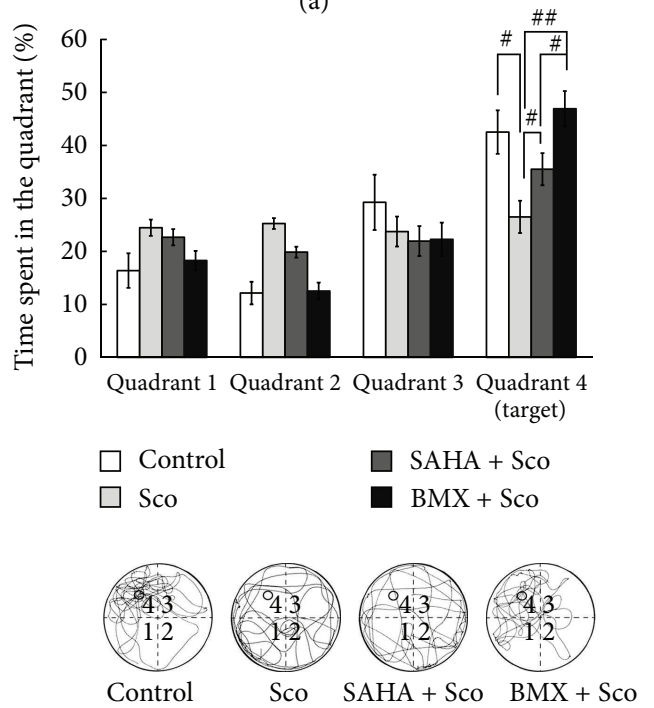

(d)

(b)

FIGURE 9: Effect of SAHA and BMX on Sco-induced memory impairment in water-maze memory acquisition and retrieval in rats. Control, scopolamine (Sco), (SAHA + Sco), and (BMX + Sco)-injected rats were subjected to water-maze training. The escape latency(s) of each watermaze learning trial ((a), upper) and the mean escape latency of each learning day ((a), lower) were recorded. On day 5, the hidden platform was removed, and the rats were allowed to swim for the probe trial test for $2 \mathrm{~min}$. The time spent in each quadrant was recorded ((b), upper). The representative swimming pattern from the probe trial test is shown ((b), lower). We analyzed the swimming speed (c) and the escape latency of each water maze learning trial in the visible platform (d) to rule out any motor, visual, or motivation side effect of drugs. The data are the mean \pm SEM. $*$, in the comparison of the control group; \#, in the comparison between groups. ${ }^{*, \#} P<0.05 ;{ }^{* *, \# \#} P<0.01$. A two-way ANOVA followed by Newman-Keuls comparisons was applied for (a) and (b). A one-way ANOVA followed by Newman-Keuls comparisons was applied for (c) and (d). 


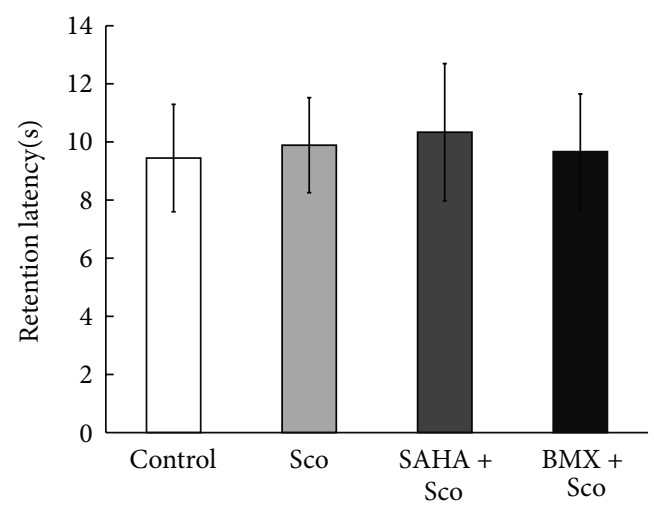

(a)

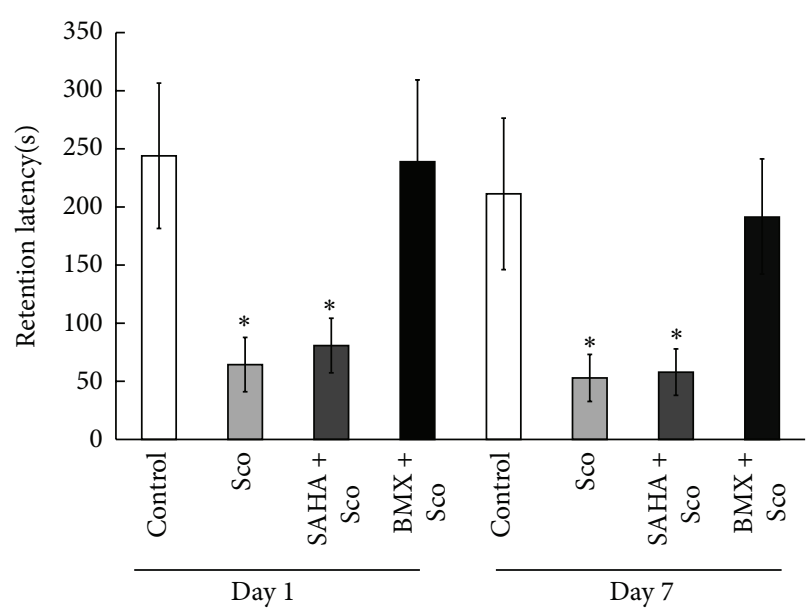

(b)

FIGURE 10: Effect of SAHA and BMX on Sco-induced memory impairment in passive one-way inhibitory avoidance learning in rats. Control, scopolamine (Sco), (SAHA + Sco), and (BMX + Sco)-injected rats were subjected to passive one-way inhibitory avoidance learning. Retention time in an illuminated compartment before footshock did not show any difference (a). Retention time in an illuminated compartment 1 day and 7 days after footshock was recorded (b). The data are the mean \pm SEM. $*$, in the comparison of the control group. ${ }^{*} P<0.05$. One-way ANOVA followed by Newman-Keuls comparisons.

In addition, the administration of Sco has been proposed as a pharmacological model for Alzheimer's disease. The administration of Sco results in the increase of $\mathrm{A} \beta$ generation and $\gamma$-secretase activity in the cortex and hippocampus [60, 62]. In addition, Sco triggers oxidative stress in the brain of rats $[63,64]$. This strengthens the value of BMX in treating memory-related diseases.

Class I HDAC inhibitors such as sodium valproate, sodium butyrate, and SAHA reversed contextual fearconditioning memory in APPswe/PS1dE9 Alzheimer's disease mice at a concentration of $100 \mathrm{mg} / \mathrm{kg}$ for 2 weeks [15], which might have caused unexpected side effects at such a high concentration. For example, TSA, with a basal toxicity and prolonged treatment at high doses, often induces neuronal death, thus compromising their neuroprotective effect [65]. Sodium butyrate inhibits HDACl, $-2,-3,-6,-8$, and -10 causing cell apoptosis [66]. Valproic acid, which inhibits HDACs 1-4 and 5-9, stops the entry of the G1 phase and also leads to cell apoptosis [67]. SAHA might damage neuronal cells through inhibition of HDACl or HDAC2 enzyme activity which cannot be ruled out $[6,17-$ 20]. Our findings reveal that BMX did not cause a neurotoxic effect, whereas SAHA, at a concentration of $2.5 \mu \mathrm{M}$, reduces cell survival in primary hippocampal neurons (Figure 5). Because of the possibility of cell damage from pan-HDAC inhibitors, BMX can be valued for its safety and isoformselective property.

In an HDAC1-11 activity assay, although BMX inhibits HDAC 3 and -8 , we proposed that BMX should only inhibit HDAC8 in vivo at the concentration $(5 \mathrm{mg} / \mathrm{kg})$ we administered. As shown in Figures 4(c) and 4(d), BMX was detected in the brain at an average concentration of approximately
$1.2 \mu \mathrm{g} / \mathrm{g}(1.2 \mathrm{ppm})$, and the plasma concentration was approximately $1 \mu \mathrm{g} / \mathrm{mL}(3 \mu \mathrm{M}) 15 \mathrm{~min}$ after intravenous $(10 \mathrm{mg} / \mathrm{kg})$ administration. In other words, for the BMX injected at $5 \mathrm{mg} / \mathrm{kg}$ as in our current behavior study, we proposed that the plasma BMX concentration should be less than $1.5 \mu \mathrm{M}$ in $15 \mathrm{~min}$, at which the concentration that blocks HDAC8 activity $\left(\mathrm{EC}_{50}=0.831 \mu \mathrm{M}\right)$ may exert only a slight effect on HDAC3 activity $\left(\mathrm{EC}_{50}=27.3 \mu \mathrm{M}\right)$. This was partially confirmed by the results that showed that BMX did not affect Histone 4 acetylation by western blotting. If BMX inhibits HDAC3, H4K12 acetylation should have raised. This is also congruent with a previous report that the HDAC8-selective inhibitor did not alter histone acetylation $[17,52]$ and $\alpha$ tubulin acetylation [68]. The substrate of HDAC8 in vivo remains unknown. Conversely, SAHA was reported to restore H4K12 acetylation loss in aged mice [13]. SAHA inhibits HDAC8 activity only at a relatively high concentration [16].

The molecular mechanism underlying the effect of BMX on enhancing memory formation must still be investigated. Two HDAC8 inhibitors, PCI34051 and Chrysin, which were identified recently, were reported to inhibit tumor growth $[68,69]$. BMX shows similar EC50 as PCI34051 on HDAC8 activity inhibition in our unpublished data. To date, few substrates for HDAC8 in vivo have been identified. HDAC8 forms a complex with PP1 and CREB and functions to inactivate CREB-mediated gene transcription [70]. This suggests that BMX may modulate CREB-associated proteins or genes to contribute to memory formation and neural plasticity. Further studies such as microarray or proteomic studies should be conducted to identify the BMX substrate and its downstream signaling molecules involved in learning and memory. 


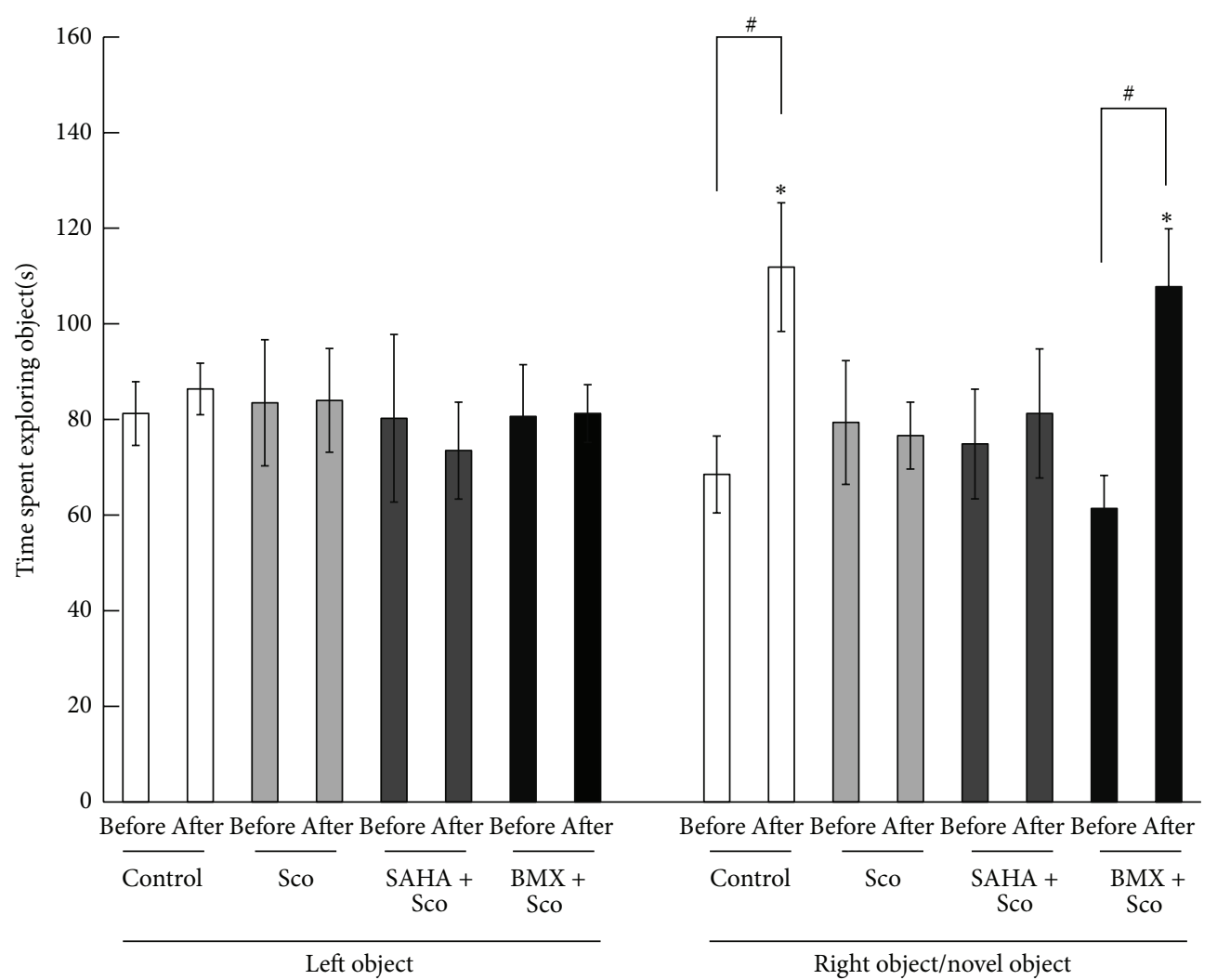

FIGURE 11: Effect of SAHA and BMX on Sco-induced memory impairment in the novel object recognition test in rats. Control, scopolamine $(\mathrm{Sco}),(\mathrm{SAHA}+\mathrm{Sco})$, and (BMX + Sco)-injected rats were subjected to the novel object recognition test. The retention time(s) spent in exploring the left object, right object, and novel object before (pre-) and after (post-) the right object was replaced with the novel object was recorded. The data are the mean \pm SEM. $*$, in the comparison of the control group; \#, in the comparison between groups. ${ }^{*, \#} P<0.05$. A two-way ANOVA followed by Newman-Keuls comparisons was applied.

\section{Conflict of Interests}

The authors declare that they have no conflict of interests.

\section{Authors' Contribution}

Ying-Chen Yang and Chia-Nan Chen should be considered as cofirst authors.

\section{Acknowledgment}

This work was partly supported by a Grant from the National Science Council of Taiwan (NSC99-2314-B-197-001-MY3).

\section{References}

[1] M. Bhasin, E. L. Reinherz, and P. A. Reche, "Recognition and classification of histones using support vector machine," Journal of Computational Biology, vol. 13, no. 1, pp. 102-112, 2006.

[2] A. Mai, S. Massa, D. Rotili et al., "Histone deacetylation in epigenetics: an attractive target for anticancer therapy," Medicinal Research Reviews, vol. 25, no. 3, pp. 261-309, 2005.

[3] D. C. Drummond, C. O. Noble, D. B. Kirpotin, Z. Guo, G. K. Scott, and C. C. Benz, "Clinical development of histone deacetylase inhibitors as anticancer agents," Annual Review of Pharmacology and Toxicology, vol. 45, pp. 495-528, 2005.
[4] X. J. Yang and E. Seto, "HATs and HDACs: from structure, function and regulation to novel strategies for therapy and prevention," Oncogene, vol. 26, no. 37, pp. 5310-5318, 2007.

[5] A. Fischer, F. Sananbenesi, X. Wang, M. Dobbin, and L. H. Tsai, "Recovery of learning and memory is associated with chromatin remodelling," Nature, vol. 447, no. 7141, pp. 178-182, 2007.

[6] D. Kim, C. L. Frank, M. M. Dobbin et al., "Deregulation of HDAC1 by p25/Cdk5 in neurotoxicity," Neuron, vol. 60, no. 5, pp. 803-817, 2008.

[7] J. S. Guan, S. J. Haggarty, E. Giacometti et al., "HDAC2 negatively regulates memory formation and synaptic plasticity," Nature, vol. 459, no. 7243, pp. 55-60, 2009.

[8] S. C. McQuown and M. A. Wood, "HDAC3 and the molecular brake pad hypothesis," Neurobiology of Learning and Memory, vol. 96, no. 1, pp. 27-34, 2011.

[9] N. Federman, M. S. Fustiñana, and A. Romano, "Histone acetylation is recruited in consolidation as a molecular feature of stronger memories," Learning \& Memory, vol. 16, no. 10, pp. 600-606, 2009.

[10] C. G. Vecsey, J. D. Hawk, K. M. Lattal et al., "Histone deacetylase inhibitors enhance memory and synaptic plasticity via CREB: CBP-dependent transcriptional activation," Journal of Neuroscience, vol. 27, no. 23, pp. 6128-6140, 2007.

[11] C. Sgobio, V. Ghiglieri, C. Costa et al., "Hippocampal synaptic plasticity, memory, and epilepsy: effects of long-term valproic 
acid treatment," Biological Psychiatry, vol. 67, no. 6, pp. 567-574, 2010.

[12] J. M. Alarcón, G. Malleret, K. Touzani et al., "Chromatin acetylation, memory, and LTP are impaired in CBP+/- mice: a model for the cognitive deficit in Rubinstein-Taybi syndrome and its amelioration," Neuron, vol. 42, no. 6, pp. 947-959, 2004.

[13] S. Peleg, F. Sananbenesi, A. Zovoilis et al., "Altered histone acetylation is associated with age-dependent memory impairment in mice," Science, vol. 328, no. 5979, pp. 753-756, 2010.

[14] E. Hockly, V. M. Richon, B. Woodman et al., "Suberoylanilide hydroxamic acid, a histone deacetylase inhibitor, ameliorates motor deficits in a mouse model of Huntington's disease," Proceedings of the National Academy of Sciences of the United States of America, vol. 100, no. 4, pp. 2041-2046, 2003.

[15] M. Kilgore, C. A. Miller, D. M. Fass et al., "Inhibitors of class 1 histone deacetylases reverse contextual memory deficits in a mouse model of alzheimer's disease," Neuropsychopharmacology, vol. 35, no. 4, pp. 870-880, 2010.

[16] D. M. Fass, S. A. Reis, B. Ghosh et al., "Crebinostat: a novel cognitive enhancer that inhibits histone deacetylase activity and modulates chromatin-mediated neuroplasticity," Neuropharmacology, vol. 64, no. 1, pp. 81-96, 2013.

[17] I. Oehme, H. E. Deubzer, D. Wegener et al., "Histone deacetylase 8 in neuroblastoma tumorigenesis," Clinical Cancer Research, vol. 15, no. 1, pp. 91-99, 2009.

[18] J. Y. Kim, S. Shen, K. Dietz et al., "HDAC1 nuclear export induced by pathological conditions is essential for the onset of axonal damage," Nature Neuroscience, vol. 13, no. 2, pp. 180-189, 2010.

[19] K. M. Miller, J. V. Tjeertes, J. Coates et al., "Human HDAC1 and HDAC2 function in the DNA-damage response to promote DNA nonhomologous end-joining," Nature Structural \& Molecular Biology, vol. 17, no. 9, pp. 1144-1151, 2010.

[20] M. Jawerka, D. Colak, L. Dimou et al., "The specific role of histone deacetylase 2 in adult neurogenesis," Neuron Glia Biology, vol. 6, no. 2, pp. 93-107, 2010.

[21] M. Mishra, J. Huang, Y. Y. Lee et al., "Gastrodia elata modulates amyloid precursor protein cleavage and cognitive functions in mice," BioScience Trends, vol. 5, no. 3, pp. 129-138, 2011.

[22] Z. Lin, J. Gu, J. Xiu, T. Mi, J. Dong, and J. K. Tiwari, "Traditional chinese medicine for senile dementia," Evidence-Based Complementary and Alternative Medicine, vol. 2012, Article ID 692621, 13 pages, 2012.

[23] B. Lee, I. Shim, H. Lee, and D. H. Hahm, "Rehmannia glutinosa ameliorates scopolamine-induced learning and memory impairment in rats," Journal of Microbiology and Biotechnology, vol. 21, no. 8, pp. 874-883, 2011.

[24] J. X. Liu, W. P. Zhang, and Q. S. Lian, "Phytoestrogen-like effect of Cnidium monnieri (L) cuss," Chinese Journal of Clinical Rehabilitation, vol. 9, no. 23, pp. 186-189, 2005.

[25] C. M. Zhang, X. Feng, and Y. Zhong, “The advancement in the chemical and pharmacological study of Cnidium monnieri (1.) cusson," Practical Pharmacy and Clinical Remedies, vol. 9, pp. 55-57, 2006.

[26] J. Allard and F. Giuliano, "Central nervous system agents in the treatment of erectile dysfunction: how do they work?" Current Urology Reports, vol. 2, no. 6, pp. 488-494, 2001.

[27] P. L. Kuo, Y. L. Hsu, C. H. Chang, and J. K. Chang, "Ostholemediated cell differentiation through bone morphogenetic protein-2/p38 and extracellular signal-regulated kinase 1/2 pathway in human osteoblast cells," Journal of Pharmacology and Experimental Therapeutics, vol. 314, no. 3, pp. 1290-1299, 2005.

[28] J. H. Guh, S. M. Yu, F. N. Ko, T. S. Wu, and C. M. Teng, "Antiproliferative effect in rat vascular smooth muscle cells by osthole, isolated from Angelica pubescens," European Journal of Pharmacology, vol. 298, no. 2, pp. 191-197, 1996.

[29] J. J. Luszczki, M. Andres-Mach, W. Cisowski, I. Mazol, K. Glowniak, and S. J. Czuczwar, "Osthole suppresses seizures in the mouse maximal electroshock seizure model," European Journal of Pharmacology, vol. 607, no. 1-3, pp. 107-109, 2009.

[30] Z. Qi, J. Xue, Y. Zhang, H. Wang, and M. Xie, "Osthole ameliorates insulin resistance by increment of adiponectin release in high-fat and high-sucrose-induced fatty liver rats," Planta Medica, vol. 77, no. 3, pp. 231-235, 2011.

[31] W. B. Liu, J. Zhou, Y. Qu et al., "Neuroprotective effect of osthole on MPP+-induced cytotoxicity in PC12 cells via inhibition of mitochondrial dysfunction and ROS production," Neurochemistry International, vol. 57, no. 3, pp. 206-215, 2010.

[32] M. T. Hsieh, C. L. Hsieh, W. H. Wang, C. S. Chen, C. J. Lin, and C. R. Wu, "Osthole improves aspects of spatial performance in ovariectomized rats," American Journal of Chinese Medicine, vol. 32, no. 1, pp. 11-20, 2004.

[33] C. R. Wu, L. W. Lin, C. L. Hsieh, W. H. Wang, Y. T. Lin, and M. T. Hsieh, "Petroleum ether extract of Cnidium monnieri ameliorated scopolamine-induced amnesia through adrenal gland-mediated mechanism in male rats," Journal of Ethnopharmacology, vol. 117, no. 3, pp. 403-407, 2008.

[34] W. J. Huang, C. C. Chen, S. W. Chao et al., "Synthesis of nhydroxycinnamides capped with a naturally occurring moiety as inhibitors of histone deacetylase," ChemMedChem, vol. 5, no. 4, pp. 598-607, 2010.

[35] J. Shi, Y. Wang, and G. Luo, "Ligustrazine phosphate ethosomes for treatment of alzheimer's disease, in vitro and in animal model studies," AAPS PharmSciTech, vol. 13, no. 2, pp. 485-492, 2012.

[36] X. Wang, Z. H. Wang, Y. Y. Wu et al., "Melatonin attenuates scopolamine-induced memory/synaptic disorder by rescuing epacs/mir-124/egrl pathway," Molecular Neurobiology, vol. 47, no. 1, pp. 373-381, 2013.

[37] C. C. Liang, C. Y. Hong, C. F. Chen, and T. H. Tsai, "Measurement and pharmacokinetic study of tetramethylpyrazine in rat blood and its regional brain tissue by high-performance liquid chromatography," Journal of Chromatography B, vol. 724, no. 2, pp. 303-309, 1999.

[38] Y. M. Tsai, C. F. Chien, L. C. Lin, and T. H. Tsai, "Curcumin and its nano-formulation: the kinetics of tissue distribution and blood-brain barrier penetration," International Journal of Pharmaceutics, vol. 416, no. 1, pp. 331-338, 2011.

[39] Y. C. Yang, C. H. Lin, and E. H. Y. Lee, "Serum- and glucocorticoid-inducible kinase 1 (SGK1) increases neurite formation through microtubule depolymerization by SGK1 and by SGK1 phosphorylation of tau," Molecular and Cellular Biology, vol. 26, no. 22, pp. 8357-8370, 2006.

[40] T. Y. Kuo, C. L. Huang, J. M. Yang et al., "The role of ribosylatedbsa in regulating pc12 cell viability," Cell Biology and Toxicology, vol. 28, no. 4, pp. 255-267, 2012.

[41] Y. C. Yang, Y. L. Ma, W. T. Liu, and E. H. Lee, "Laminin-betal impairs spatial learning through inhibition of erk/mapk and sgk1 signaling," Neuropsychopharmacology, vol. 36, no. 12, pp. 2571-2586, 2011. 
[42] W. Classen and C. Mondadori, "Facilitation or inhibition of memory by morphine: a question of experimental parameters," Experientia, vol. 40, no. 5, pp. 506-509, 1984.

[43] H. G. Van Oyen, N. E. Van De Poll, and J. P. C. De Bruin, "Sex, age and shock-intensity as factors in passive avoidance," Physiology and Behavior, vol. 23, no. 5, pp. 915-918, 1979.

[44] K. Tóth, K. László, E. Lukács, and L. Lénárd, "Intraamygdaloid microinjection of acylated-ghrelin influences passive avoidance learning," Behavioural Brain Research, vol. 202, no. 2, pp. 308311, 2009.

[45] A. M. Huang, H. L. Wang, Y. P. Tang, and E. H. Y. Lee, "Expression of integrin-associated protein gene associated with memory formation in rats," Journal of Neuroscience, vol. 18, no. 11, pp. 4305-4313, 1998.

[46] G. Arqué, V. Fotaki, D. Fernández, M. M. de Lagrán, M. L. Arbonés, and M. Dierssen, "Impaired spatial learning strategies and novel object recognition in mice haploinsufficient for the dual specificity tyrosine-regulated kinase-1A (Dyrk1A)," PLoS ONE, vol. 3, no. 7, Article ID e2575, 2008.

[47] J. B. Lee, J. Wei, W. Liu, J. Cheng, J. Feng, and Z. Yan, "Histone deacetylase 6 gates the synaptic action of acute stress in prefrontal cortex," Journal of Physiology, vol. 590, part 7, pp. 1535-1546, 2012.

[48] S. J. Park, D. H. Kim, J. M. Jung et al., "The ameliorating effects of stigmasterol on scopolamine-induced memory impairments in mice," European Journal of Pharmacology, vol. 676, no. 1-3, pp. 64-70, 2012.

[49] J. Chen, Y. Long, M. Han, T. Wang, Q. Chen, and R. Wang, "Water-soluble derivative of propolis mitigates scopolamineinduced learning and memory impairment in mice," Pharmacology Biochemistry and Behavior, vol. 90, no. 3, pp. 441-446, 2008.

[50] D. H. Kim, S. J. Park, J. M. Kim et al., "Cognitive dysfunctions induced by a cholinergic blockade and abeta $25-35$ peptide are attenuated by salvianolic acid b," Neuropharmacology, vol. 61, no. 8, pp. 1432-1440, 2011.

[51] M. Haberland, M. H. Mokalled, R. L. Montgomery, and E. N. Olson, "Epigenetic control of skull morphogenesis by histone deacetylase 8," Genes \& Development, vol. 23, no. 14, pp. 16251630, 2009.

[52] I. Oehme, H. E. Deubzer, M. Lodrini, T. Milde, and O. Witt, "Targeting of HDAC8 and investigational inhibitors in neuroblastoma," Expert Opinion on Investigational Drugs, vol. 18, no. 11, pp. 1605-1617, 2009.

[53] D. A. Frank and M. E. Greenberg, "CREB: a mediator of longterm memory from mollusks to mammals," Cell, vol. 79, no. 1, pp. 5-8, 1994.

[54] S. B. McHugh, T. G. Campbell, A. M. Taylor, J. N. P. Rawlins, and D. M. Bannerman, "A role for dorsal and ventral hippocampus in inter-temporal choice cost-benefit decision making," Behavioral Neuroscience, vol. 122, no. 1, pp. 1-8, 2008.

[55] N. J. Broadbent, L. R. Squire, and R. E. Clark, "Spatial memory, recognition memory, and the hippocampus," Proceedings of the National Academy of Sciences of the United States of America, vol. 101, no. 40, pp. 14515-14520, 2004.

[56] A. Ennaceur and J. Delacour, "A new one-trial test for neurobiological studies of memory in rats. 1: behavioral data," Behavioural Brain Research, vol. 31, no. 1, pp. 47-59, 1988.

[57] N. Plath, O. Ohana, B. Dammermann et al., "Arc/arg3. 1 is essential for the consolidation of synaptic plasticity and memories," Neuron, vol. 52, no. 3, pp. 437-444, 2006.
[58] V. Ramírez-Amaya, A. Vazdarjanova, D. Mikhael, S. Rosi, P. F. Worley, and C. A. Barnes, "Spatial exploration-induced Arc mRNA and protein expression: evidence for selective, networkspecific reactivation," Journal of Neuroscience, vol. 25, no. 7, pp. 1761-1768, 2005.

[59] D. P. Stefanko, R. M. Barrett, A. R. Ly, G. K. Reolon, and M. A. Wood, "Modulation of long-term memory for object recognition via HDAC inhibition," Proceedings of the National Academy of Sciences of the United States of America, vol. 106, no. 23, pp. 9447-9452, 2009.

[60] D. Y. Choi, Y. J. Lee, S. Y. Lee et al., "Attenuation of scopolamineinduced cognitive dysfunction by obovatol," Archives of Pharmacal Research, vol. 35, no. 7, pp. 1279-1286, 2012.

[61] R. D’Hooge and P. P. De Deyn, "Applications of the Morris water maze in the study of learning and memory," Brain Research Reviews, vol. 36, no. 1, pp. 60-90, 2001.

[62] W. Liskowsky and R. Schliebs, "Muscarinic acetylcholine receptor inhibition in transgenic Alzheimer-like Tg2576 mice by scopolamine favours the amyloidogenic route of processing of amyloid precursor protein," International Journal of Developmental Neuroscience, vol. 24, no. 2-3, pp. 149-156, 2006.

[63] Y. Fan, J. Hu, J. Li et al., "Effect of acidic oligosaccharide sugar chain on scopolamine-induced memory impairment in rats and its related mechanisms," Neuroscience Letters, vol. 374, no. 3, pp. 222-226, 2005.

[64] S. H. Kwon, H. K. Lee, J. A. Kim et al., "Neuroprotective effects of chlorogenic acid on scopolamine-induced amnesia via anti-acetylcholinesterase and anti-oxidative activities in mice," European Journal of Pharmacology, vol. 649, no. 1-3, pp. 210-217, 2010.

[65] A. Salminen, T. Tapiola, P. Korhonen, and T. Suuronen, "Neuronal apoptosis induced by histone deacetylase inhibitors," Molecular Brain Research, vol. 61, no. 1-2, pp. 203-206, 1998.

[66] J. R. Davie, "Inhibition of histone deacetylase activity by butyrate," Journal of Nutrition, vol. 133, no. 7, supplement, pp. 2485S-2493S, 2003.

[67] Ø. Bruserud, C. Stapnes, E. Ersvær, B. T. Gjertsen, and A. Ryningen, "Histone deacetylase inhibitors in cancer treatment: a review of the clinical toxicity and the modulation of gene expression in cancer cells," Current Pharmaceutical Biotechnology, vol. 8, no. 6, pp. 388-400, 2007.

[68] S. Balasubramanian, J. Ramos, W. Luo, M. Sirisawad, E. Verner, and J. J. Buggy, "A novel histone deacetylase 8 (HDAC8)-specific inhibitor PCI-34051 induces apoptosis in T-cell lymphomas," Leukemia, vol. 22, no. 5, pp. 1026-1034, 2008.

[69] L. P. Sun, A. L. Chen, H. C. Hung et al., "Chrysin: a histone deacetylase 8 inhibitor with anticancer activity and a suitable candidate for standardization of chinese propolis," Journal of Agricultural and Food Chemistry, vol. 60, no. 47, pp. 11748-11758, 2012.

[70] J. Gao, B. Siddoway, Q. Huang, and H. Xia, "Inactivation of CREB mediated gene transcription by HDAC8 bound protein phosphatase," Biochemical and Biophysical Research Communications, vol. 379, no. 1, pp. 1-5, 2009. 


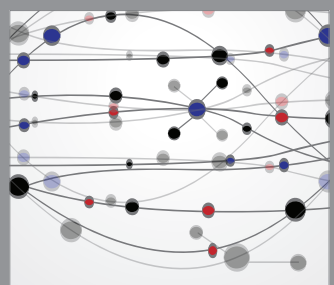

The Scientific World Journal
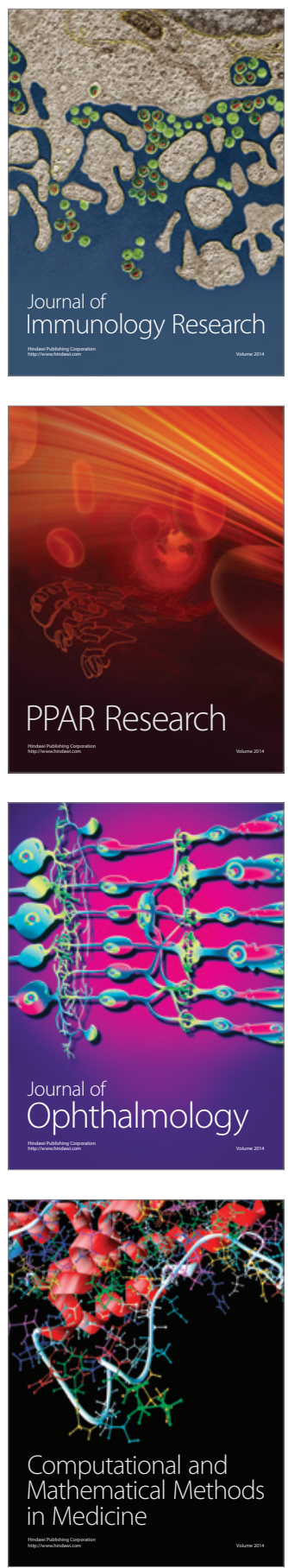

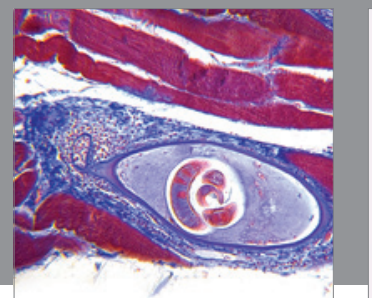

Gastroenterology

Research and Practice
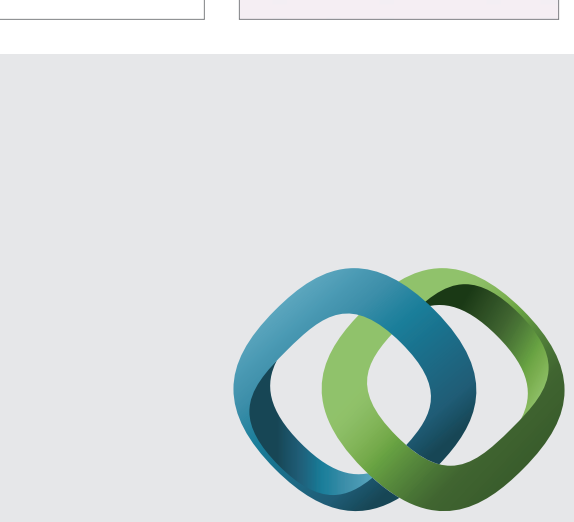

\section{Hindawi}

Submit your manuscripts at

http://www.hindawi.com
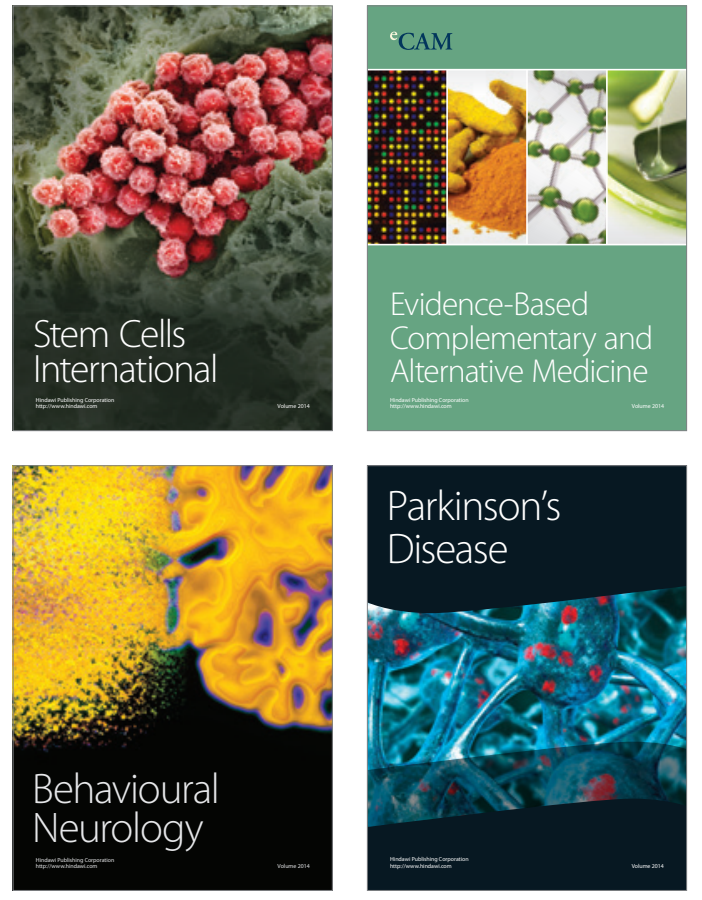
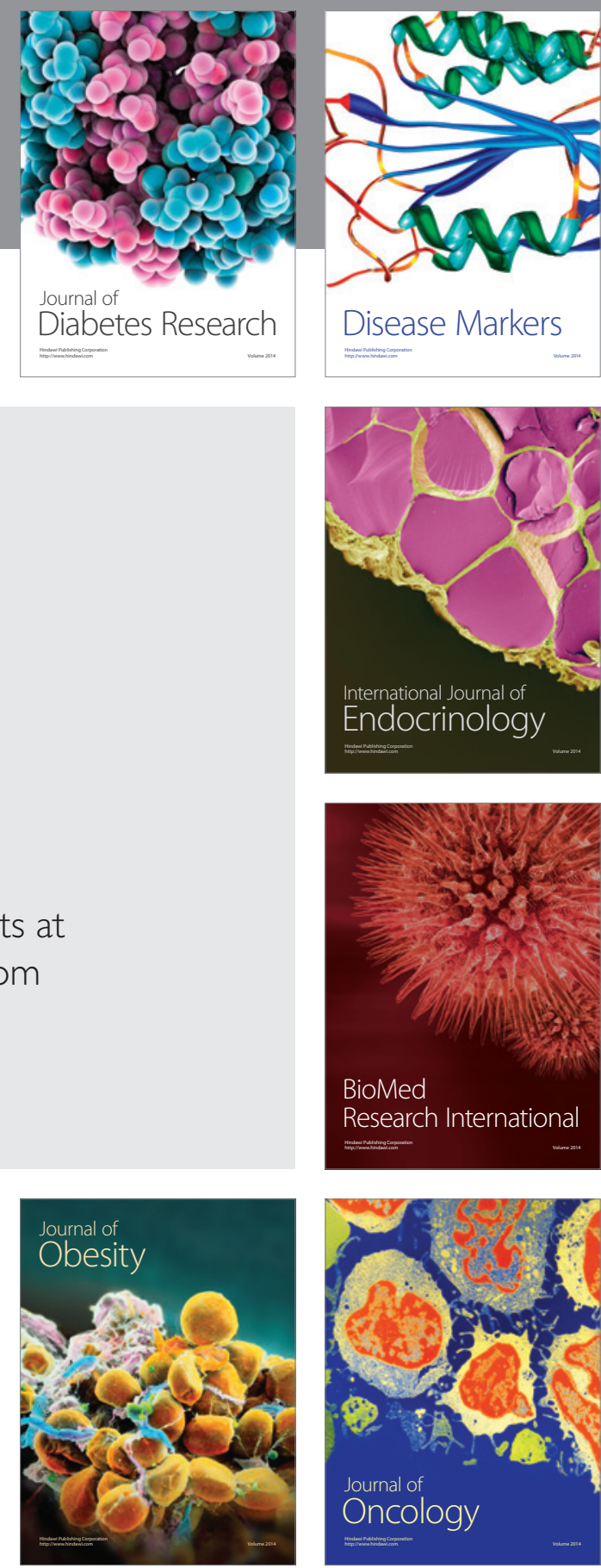

Disease Markers
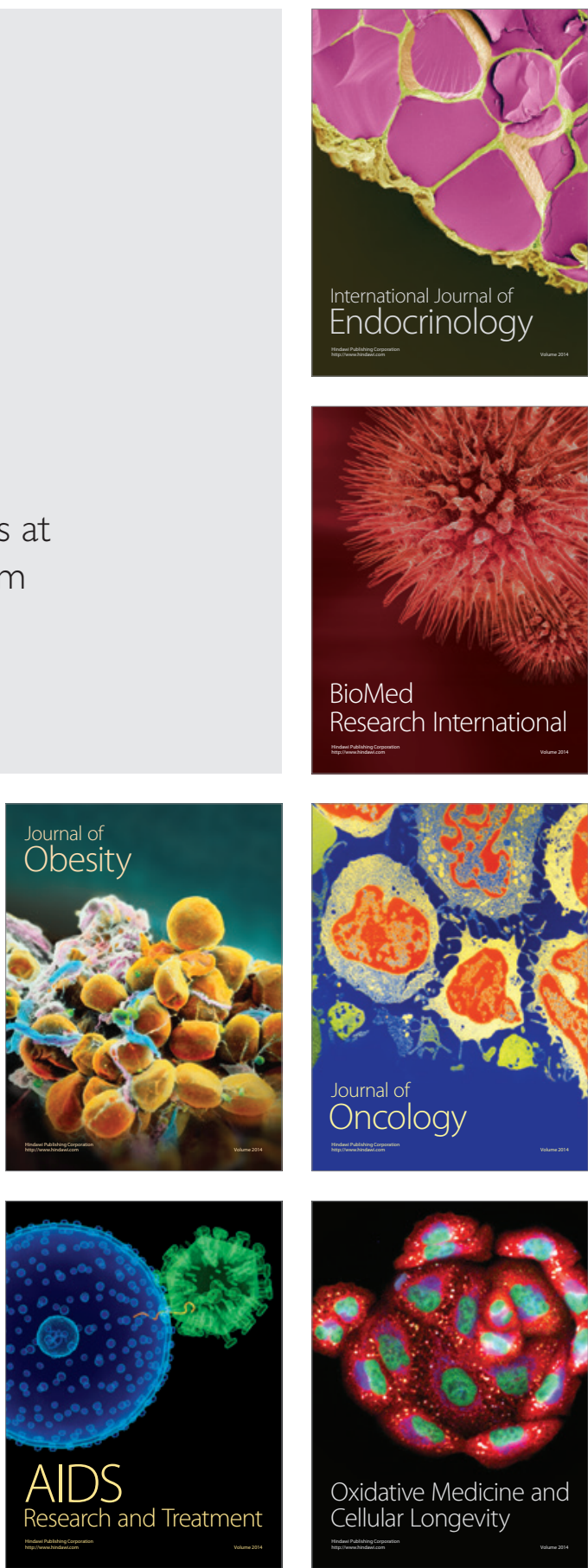